\title{
Statistical Approach to Optimize the Process Parameters of HAZ of Tool Steel EN X32CrMoV12-28 after Die-Sinking EDM with SF-Cu Electrode
}

\author{
L'uboslav Straka $^{1, *}$, Ivan Čorný ${ }^{2}$, Ján Pitel ${ }^{3}$ and Slavomíra Hašová ${ }^{1}$ \\ 1 Department of Manufacturing Processes Operation, The Technical University of Košice, Štúrova 31, \\ 08001 Prešov, Slovakia; slavomira.hasova@tuke.sk \\ 2 Department of Science and Research, The Technical University of Košice, Bayerova 1, 08001 Prešov, Slovakia; \\ ivan.corny@tuke.sk \\ 3 Department of Mathematics, Informatics and Cybernetics, The Technical University of Košice, Bayerova 1, \\ 08001 Prešov, Slovakia; jan.pitel@tuke.sk \\ * Correspondence: luboslav.straka@tuke.sk; Tel.: +421-55-602-6346
}

Academic Editor: Hugo F. Lopez

Received: 13 December 2016; Accepted: 20 January 2017; Published: 27 January 2017

\begin{abstract}
The paper describes the results of the experimental research of the heat affected zone (HAZ) of an eroded surface after die-sinking electrical discharge machining (EDM). The research was carried out on chrome-molybdenum-vanadium alloyed tool steel EN X32CrMoV12-28 (W.-Nr. 1.2365) after die-sinking EDM with a SF-Cu electrode. The aim of the experimental measurements was to contribute to the database of knowledge that characterizes the significant impact of the main technological and process parameters on the eroded surface properties during die-sinking EDM. The quality of the eroded surface was assessed from the viewpoint of surface roughness, microhardness variation, and the total HAZ depth of the thin sub-surface layer adjacent to the eroded surface. On the basis of measurement results, mathematical models were established by statistical methods. These models can be applied for computer simulation and prediction of the resultant quality of the machined surface after die-sinking EDM. The results achieved by simulation were compared with the results of experimental measurements and high correlation indexes between the predicted and real values were achieved. Suggested mathematical models can be also applied for the determination of the optimal combination of significant technological parameters in order to minimize microhardness and total HAZ depth variations of tool steel EN X32CrMoV12-28 after die-sinking EDM with a SF-Cu electrode.
\end{abstract}

Keywords: electro-erosion; microhardness; affected zone; tool steel; electrode

\section{Introduction}

Electrical discharge machining (EDM) is in general characterized by thermal processes that take place directly on the eroded surface and proceed into the inner material. Therefore, it can be expected that certain microstructural changes occur in the thin sub-surface layer also called the heat affected zone (HAZ). This phenomenon has been mentioned by many researchers, to name a few: Kompella et al., Ťavodová, and Choudhary et al. [1-3]. The researchers claim in their papers, that the surfaces of the material before, and after EDM differ substantially. They put an emphasis mainly on the significance of qualitative parameters such as surface microhardness and the total HAZ depth. The microhardness variation in HAZ is also accompanied by a change of the microstructure, the fact mentioned in Shrestha's research [4]. The microhardness variation in HAZ is typically manifested by its decline, which has in many cases an adverse impact on the products' functional surfaces produced 
by die-sinking EDM technology. These assumptions have also been confirmed by the studies of many authors, of whom we can mention Čada, Švecová, and Abu Zeid [5-7]. The authors state in their articles that particularly in this regard, tool steel products such as shearing tools, and molds are the most susceptible. According to Marafona [8], there is occurrence of a so-called black layer (BL) directly on the surface of tool steels after die-sinking EDM. However, the black layer has not shown such an adverse impact on machined surface quality as the presence of a so-called white layer (WL) which is located just below the black layer. The creation of the white layer is caused by the action of high temperature on the machined surface followed by rapid cooling (quenching). WL represents the structure after secondary hardening as a consequence of the conversion of the residual austenite. The thickness of the WL falls into the $\mu \mathrm{m}$ range. According to Ekmekci and Zang [9,10], due to heating and subsequent rapid cooling by dielectric liquid, additional residual stresses are generated in the HAZ. The size and extent of residual stresses in the HAZ depends on the combination of electrical discharge intensity and the cooling effect of the dielectric fluid. These residual stresses often result in the formation of microcracks, which undermine the overall integrity of the machined surface. Removal of these microcracks is in practice very difficult, particularly in very hard materials such as hardened tool steels. Not all studies, however, indicate an adverse impact of the presence of the HAZ in tool steels. However, a small group of researchers, which include Dewangan and Sidhom [11,12], mention benefits of the presence of the HAZ over a certain period of technical life of the tool produced by die-sinking EDM technology. This is in particular the period of the first phase of the life-cycle of the tool, in which the integrity of the WL is not compromised. During this period, the tools produced by die-sinking EDM show increased durability compared to the tools made by traditional technologies. On the contrary, when WL is damaged [13], a higher wear occurs on the functional surfaces of the tool produced by die-sinking EDM when compared to the tool produced e.g., by milling. The overview shows that the heat affecting extent presents a significant impact on performance and life-cycle of tools made by progressive technology of die-sinking EDM. Suitable control of the heat affecting extent in sub-surface layers of eroded material, in terms of microhardness variation, should result in an increase of the durability and the working life of tools produced by this technology. Proper setting of significant technological and process parameters of EDM is essential to achieve a surface with predefined specific properties. The aim of the experimental research, therefore, was to contribute to the existing knowledge database by clearly articulating the particular laws in relation to the processes that occur directly below the eroded surface. Relying on the results of experimental measurements of the quality of machined surface reached in terms of microhardness variation, and the total HAZ depth of chrome-molybdenum-vanadium alloyed tool steel EN X32CrMoV12-28 (W.-Nr. 1.2365), mathematical models were designed using statistical methods. The purpose of the models is efficient computer simulation and prediction of the final quality of the machined surface in terms of the observed qualitative indicators on the basis of an appropriate combination of significant technological and process parameters.

\section{Materials and Methods}

As was already mentioned, the resulting structure of the subsurface layer of the eroded surface and its properties have a significant influence on the durability and service life of tools (e.g., parts of molds, shearing tools, etc.), produced by die-sinking EDM technology. Nevertheless, the quality of the machined surface after die-sinking EDM is often evaluated solely on the basis of selected parameters of roughness. These quality parameters are defined in detail in the valid standard EN ISO 4287 [14]. However, particular parameters of roughness of machined surfaces fail to include important parameters related to the microstructure changes of the sub-surface layers of the machined surfaces. In general, the microstructure change of metal materials is accompanied by a change of microhardness. This change occurs as a result of the influence of the secondary hardening caused by extreme heat effects of electrical discharge between the tool and the workpiece, with the consequent rapid cooling by dielectric fluid. On the basis of the facts mentioned above, it can be considered that 
microhardness measurement is the appropriate method for evaluating changes in the microstructure of the sub-surface layers after die-sinking EDM. A detailed procedure of Vickers's microhardness test is defined in standard EN ISO 6507 [15]. In addition to the characteristic change of the material microhardness in HAZ after die-sinking EDM, the total HAZ depth is also a decisive parameter. The change of microhardness and total HAZ depth is primarily dependent on the physical, mechanical, and chemical properties of the machined material. It is also dependent on the setting range of the main technological and process parameters. Table 1 shows the overview of the main technological parameters for die-sinking EDM that in general have an essential influence on microhardness change, and also have a direct impact on the total HAZ depth.

Table 1. Setting range of the main technological parameters for die-sinking electrical discharge machining (EDM), and their anticipated impact on the change of microhardness and the total depth of the heat affected zone (HAZ).

\begin{tabular}{|c|c|c|c|c|}
\hline $\begin{array}{l}\text { Technological } \\
\text { Parameters }\end{array}$ & Operation & Setting Range & $\begin{array}{l}\text { Influence of Technological } \\
\text { Parameter on Microhardness }\end{array}$ & $\begin{array}{l}\text { Influence of Technological } \\
\text { Parameter on HAZ }\end{array}$ \\
\hline Peak current $I$ (A) & $\begin{array}{l}\text { roughing } \\
\text { semifinishing } \\
\text { finishing }\end{array}$ & $\begin{array}{c}40.0-60.0 \\
10.0-40.0 \\
2.0-10.0\end{array}$ & $\begin{array}{l}\text { With an increase of value of } \\
\text { parameter I microhardness grows. }\end{array}$ & $\begin{array}{l}\text { With an increase of value of } \\
\text { parameter I total HAZ depth } \\
\text { grows markedly. }\end{array}$ \\
\hline $\begin{array}{l}\text { Pulse on-time } \\
\text { duration } t_{\text {on }}(\mu s)\end{array}$ & $\begin{array}{l}\text { roughing } \\
\text { semifinishing } \\
\text { finishing }\end{array}$ & $\begin{array}{c}150.0-300.0 \\
50.0-150.0 \\
5.0-50.0\end{array}$ & $\begin{array}{l}\text { With an increase of value of } \\
\text { parameter } t_{\text {on }} \text { microhardness } \\
\text { grows markedly. }\end{array}$ & $\begin{array}{l}\text { With an increase of value of } \\
\text { parameter } t_{\text {on }} \text { total HAZ } \\
\text { depth grows markedly. }\end{array}$ \\
\hline $\begin{array}{c}\text { Voltage of } \\
\text { discharge } U(\mathrm{~V})\end{array}$ & $\begin{array}{l}\text { roughing } \\
\text { semifinishing } \\
\text { finishing }\end{array}$ & $\begin{array}{l}70-90 \\
70-95 \\
75-95\end{array}$ & $\begin{array}{l}\text { With a change of value of } \\
\text { parameter } U \text { microhardness varies } \\
\text { only slightly. }\end{array}$ & $\begin{array}{c}\text { With a change of value of } \\
\text { parameter } U \text { total HAZ depth } \\
\text { varies only slightly. }\end{array}$ \\
\hline
\end{tabular}

Table 1 shows the expected impact of the main technological parameters, i.e., peak current $I$, pulse on-time duration $t_{\mathrm{on}}$, related pause for recovery of a discharge channel-pulse off-time duration $t_{\mathrm{off}}$, and voltage of discharge $U$, during die-sinking EDM, on microhardness change and total HAZ depth.

As mentioned above, microhardness change and total HAZ depth is also dependent on process parameters. The overview of the main process parameters for die-sinking EDM, which substantially affect the change of microhardness and have a direct impact on the total depth of the HAZ, is given in Table 2.

Table 2. Setting range of process parameters at die-sinking EDM with a SF-Cu electrode of $\phi 20 \mathrm{~mm}$ diameter, and their expected impact on microhardness change and total HAZ depth.

\begin{tabular}{|c|c|c|c|c|}
\hline Processing Parameters & Operation & $\begin{array}{l}\text { Setting } \\
\text { Range }\end{array}$ & $\begin{array}{c}\text { Influence of Processing } \\
\text { Parameter on Microhardness }\end{array}$ & $\begin{array}{l}\text { Influence of Processing } \\
\text { Parameter on HAZ }\end{array}$ \\
\hline $\begin{array}{l}\text { Feed rate of the tool } \\
\text { electrode } v_{f}\left(\mathrm{~mm} \cdot \mathrm{min}^{-1}\right)\end{array}$ & $\begin{array}{l}\text { roughing } \\
\text { semifinishing } \\
\text { finishing }\end{array}$ & $\begin{array}{c}0.2-0.4 \\
0.1-0.2 \\
0.05-0.1\end{array}$ & $\begin{array}{l}\text { With an increase of value of } \\
\text { parameter } v_{f} \text { microhardness } \\
\text { grows only slightly. }\end{array}$ & $\begin{array}{c}\text { With an increase of value of } \\
\text { parameter } v_{f} \text { total HAZ depth } \\
\text { grows marginally. }\end{array}$ \\
\hline $\begin{array}{c}\text { Intensity of the volumetric } \\
\text { material removal } \\
\operatorname{MRR}\left(\mathrm{mm}^{3} \cdot \mathrm{min}^{-1}\right)\end{array}$ & $\begin{array}{l}\text { roughing } \\
\text { semifinishing } \\
\text { finishing }\end{array}$ & $\begin{array}{c}60.0-120.0 \\
30.0-60.0 \\
15.0-30.0\end{array}$ & $\begin{array}{l}\text { With an increase of value of } \\
\text { parameter MRR microhardness } \\
\text { grows substantially. }\end{array}$ & $\begin{array}{l}\text { With an increase of value of } \\
\text { parameter MRR total HAZ } \\
\text { depth grows markedly. }\end{array}$ \\
\hline
\end{tabular}

Table 2 shows the setting range of process parameters, i.e., feed rate of the tool electrode $v_{f}$, and intensity of the volumetric material removal (MRR) during die-sinking EDM with a SF-Cu electrode of $\$ 20 \mathrm{~mm}$ diameter. Table 2 also shows the expected impact of the given process parameters on the microhardness change and total HAZ depth.

\subsection{Equipment and Tools Used in Experiments}

The experimental samples were made using a CNC electrical discharge machining facility (Figure 1) Sodick AG60L Sinker EDM (Sodick Europe Ltd., Rowley Drive, Baginton, UK). The tool 
applied in machining was a cylindrical SF-Cu electrode with dimension $\phi 20 \times 60 \mathrm{~mm}$. Die-sinking EDM was performed in dielectric liquid on the basis of non-ionized water with electric conductivity less than $10 \mu \mathrm{S} \cdot \mathrm{cm}^{-1}$.

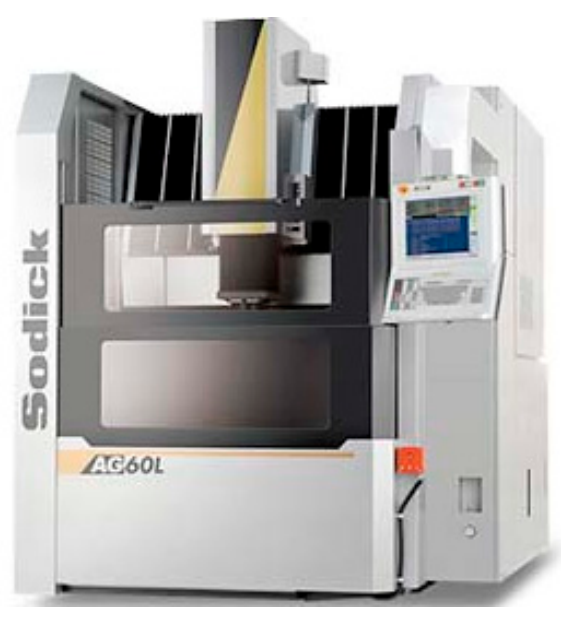

(a) Sinker EDM
Technical specification of Sodick AG60L Sinker EDM [16]

Max. Axis Travel X/Y/Z ........ $600 \times 420 \times 370 \mathrm{~mm}$

Max. Work Table Size ............. $750 \times 550$ mm

Max. Work Tank Size .............. $950 \times 740 \times 460$ mm

Fluid Level $(\min \sim \max )$......... $150 \times 400 \mathrm{~mm}$

Max. Work Tank Capacity....... 330 liters

Max. Workpiece Weight ......... 1,500 kg

Max. Electrode Weight............ $120 \mathrm{~kg}$

Geometrical Tolerance............... $\pm 3 \mu \mathrm{m}$

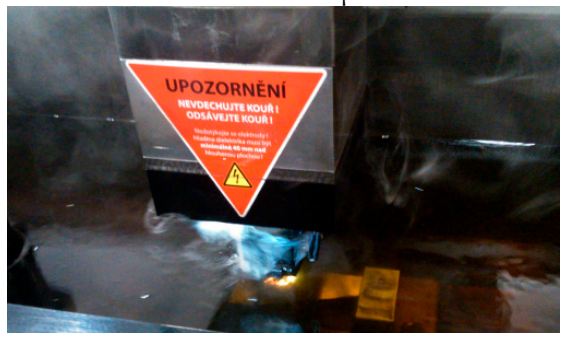

(b) workpiece

Figure 1. CNC Sodick AG60L Sinker EDM.

Table 3 shows basic mechanical properties and chemical composition of SF-Cu material which was used for the die-sinking EDM electrode production.

Table 3. Basic mechanical properties and chemical composition of SF-Cu electrode material [17].

\begin{tabular}{cccccccccc}
\hline \multirow{3}{*}{ Electrode Labeling } & \multicolumn{4}{c}{ Chemical Composition in \% } & & \multicolumn{2}{c}{ Mechanical Properties } \\
\cline { 2 - 5 } & $\mathbf{C u}$ & $\mathbf{Z n}$ & $\mathbf{A l}$ & $\mathbf{B i}$ & $\mathbf{P b}$ & $\begin{array}{c}\text { After Annealing } \\
\text { HB max. }\end{array}$ & $\begin{array}{c}\text { Tensile Strength } \\
\text { MPa min. }\end{array}$ \\
\hline SF-Cu (W.-Nr. 2.0090) & 99.8 & 0.057 & 0.15 & 0.0011 & 0.0008 & 65 & 210 \\
\hline
\end{tabular}

\subsection{Production of Experimental Samples}

In the experiments, samples made from steel block of dimensions $70 \times 40 \times 10 \mathrm{~mm}$ were used. The experimental block was made from medium-alloyed tool steel EN X32CrMoV12-28 (W.-Nr. 1.2365, STN 19 541). Tensile strength limit (TS) after heat treatment (martensitic hardening + tempering for removal of internal stresses) of the material EN X32CrMoV12-28 ranges from $1250 \mathrm{MPa}$, at basic material (BM) hardness approx. $40 \mathrm{HRC}$, to $1850 \mathrm{MPa}$ at BM hardness approx. $52 \mathrm{HRC}$. The material is medium alloyed chrome-molybdenum-vanadium tool steel with the following alloying element content: $0.28 \%-0.35 \% \mathrm{C}, 2.7 \%-3.2 \% \mathrm{Cr}$, and $2.6 \%-3.0 \%$ Mo. The material has at $20{ }^{\circ} \mathrm{C}$ low heat conductivity $\left(30 \mathrm{Wm}^{-1} \cdot \mathrm{K}^{-1}\right)$, and high electrical conductivity $\left(2.70\right.$ Siemens $\cdot \mathrm{m} \cdot \mathrm{mm}^{-2}$ ) so it is suitable for machining by die-sinking EDM technology. The material is mostly used for production of highly stressed tools for increased temperature applications, e.g., for processing of alloys containing heavy metals. These are the components such as pressing brackets and matrixes, die forging inserts, highly stressed parts of molds for pressure die casting, shearing tools, etc. The material is characterized by high temperature strength and tempering resistance, good resistance to burn-off, and good thermal conductivity. At the same time the material exhibits very good resistance to formation of heat-caused microcracks, and low sensitivity to sudden changes of temperature. Table 4 describes the basic chemical composition of tool steel EN X32CrMoV12-28 that was used for production of the experimental samples. 
Table 4. Basic chemical composition of tool steel EN X32CrMoV12-28 [18].

\begin{tabular}{|c|c|c|c|c|c|c|c|c|c|c|}
\hline \multirow{3}{*}{ Steel Labeling } & \multirow{2}{*}{\multicolumn{8}{|c|}{ Chemical Composition in \% }} & \multicolumn{2}{|c|}{ Hardness in State } \\
\hline & & & & & & & & & \multirow{2}{*}{$\begin{array}{c}\begin{array}{c}\text { Soft } \\
\text { Annealed }\end{array} \\
\text { HB max. }\end{array}$} & \multirow{2}{*}{$\begin{array}{c}\text { Refined } \\
\text { HRC } \\
\text { min. }\end{array}$} \\
\hline & $\mathrm{C}$ & $\mathrm{Si}$ & Mn & $\mathrm{Cr}$ & Mo & $\mathbf{V}$ & $P$ max. & $S$ max. & & \\
\hline EN X32CrMoV12-28 & $0.28-0.35$ & $0.1-0.4$ & $0.15-0.45$ & $2.7-3.2$ & $2.6-3.0$ & $0.4-0.7$ & 0.03 & 0.03 & 230 & 52 \\
\hline
\end{tabular}

The metal block of tool steel EN X32CrMoV12-28 was heat-treated before the experimental die-sinking EDM. The required hardness of $52 \mathrm{HRC}$ and the material tensile strength of $1850 \mathrm{MPa}$ were reached by martensitic hardening in oil at a temperature of about $1040{ }^{\circ} \mathrm{C}$, followed by tempering at about $450^{\circ} \mathrm{C}$ [18]. From the diagram on Figure 2 it can be seen that low tempering temperature (up to about $500^{\circ} \mathrm{C}$ ) has almost no effect on reducing the hardness of the basic material. Therefore, this material is suitable for tools that operate at elevated temperatures.

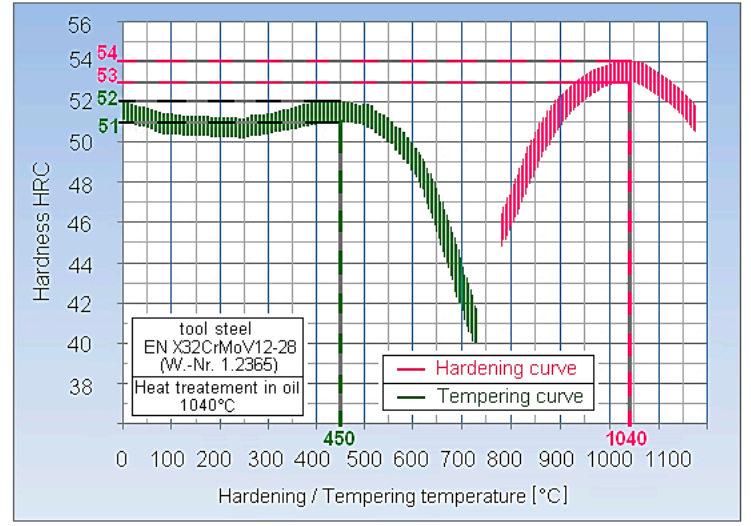

(a) hardening and tempering diagram

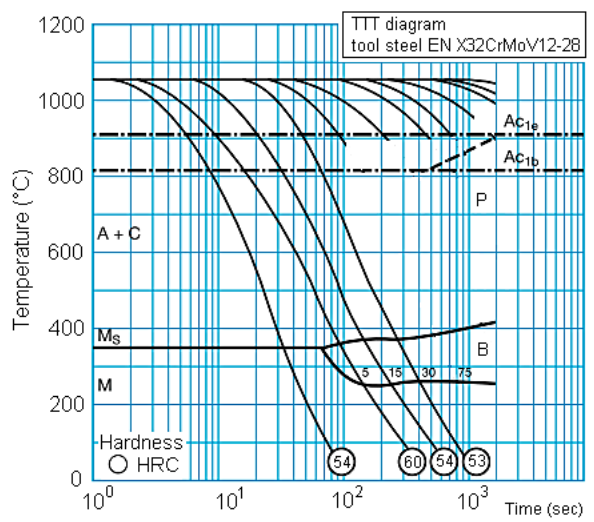

(b) Time Temperature Transformation (TTT) diagram

Figure 2. Hardening, tempering and TTT diagram of tool steel EN X32CrMoV12-28 [18].

Standard tempering temperature for the tool steels is around $200-250{ }^{\circ} \mathrm{C}$. Since the tool steel EN $\mathrm{X} 32 \mathrm{CrMoV} 12-28$ is stable at elevated temperatures, stress relief tempering had to be done at $450{ }^{\circ} \mathrm{C}$. This temperature ensures a significant reduction of material internal stress after martensitic hardening, while the decrease of BM hardness is minimal.

Figure 3 shows the eroded areas of the experimental samples of tool steel EN X32CrMoV12-28 using a SF-Cu electrode after roughing, semifinishing, and finishing operations.

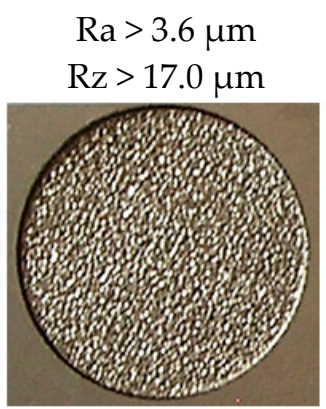

(a) roughing
$3.6 \mu \mathrm{m}>\mathrm{Ra}>2.5 \mu \mathrm{m}$

$17.0 \mu \mathrm{m}>\mathrm{Rz}>8.0 \mu \mathrm{m}$

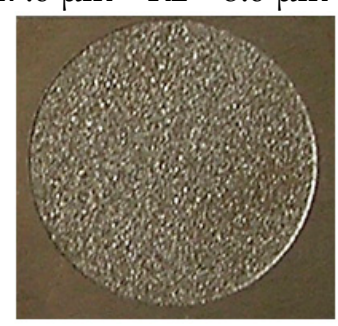

(b) semifinishing

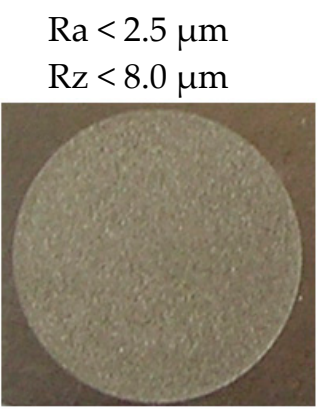

(c) finishing

Figure 3. Eroded areas of experimental samples from tool steel EN X32CrMoV12-28 after die-sinking EDM roughing, semifinishing, and finishing with SF-Cu electrode. 
Photographs in Figure 3 illustrate the essential differences of the character of machined surfaces after die-sinking EDM with a SF-Cu electrode. The machined surface after the roughing operation (Figure 3a) shows an extremely varied topography and coarse structure, on the contrary, the surface after the finishing operation (Figure 3c) has a very fine surface structure and is smooth. For higher resolution, the surface of the experimental samples of tool steel EN X32CrMoV12-28 after die-sinking EDM was observed using a digital microscope Keyence VHX-5000 (Keyence International, Mechelen, Belgium) with $500 \times$ magnification. On the eroded surface, a characteristic change of relief and microstructure compared to the basic material (Figure 4) was observed. Surface integrity remained preserved. At the same time no significant microcracks or other surface discontinuities were observed. This can be attributed to the proper combination of the main technological and process parameters, in combination with the appropriate heat treatment of the experimental samples. Figure $4 \mathrm{~b}, \mathrm{c}$ show, besides microstructure change, also the presence of small metal particles out-melted from the SF-Cu electrode.

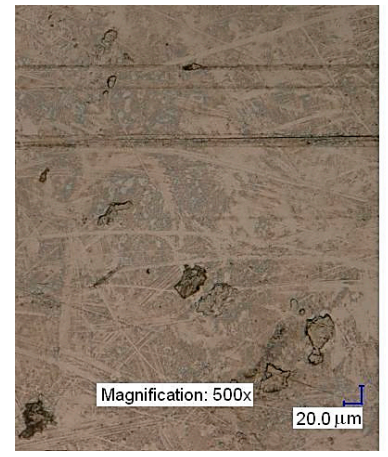

(a) before die-sinking EDM

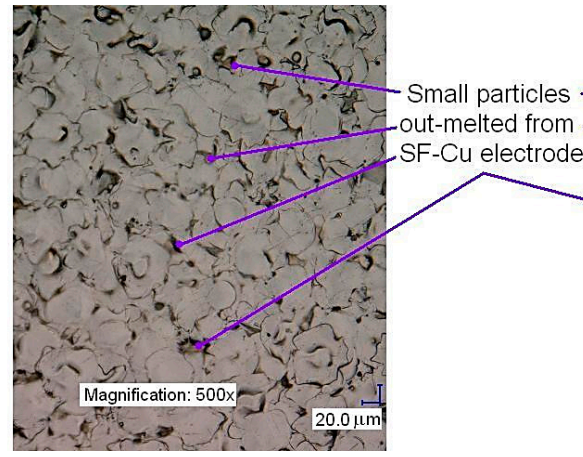

(b) after roughing

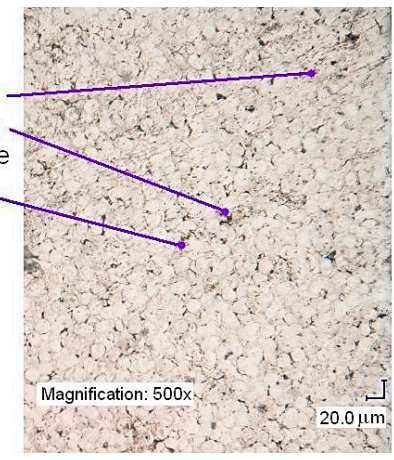

(c) after finishing

Figure 4. Characteristic change of relief and microstructure of the surface of the material EN X32CrMoV12-28 after die-sinking EDM, roughing, and finishing in comparison to the source material, magnification $500 \times$.

\subsection{Measurements of Microhardness and Total HAZ Depth}

The regular HAZ of the material EN X32CrMoV12-28 after die-sinking EDM, after roughing and finishing is created by several separate layers. Immediately after die-sinking EDM roughing, it is possible to observe a so called black layer (BL) visually—without any instruments—on the untreated eroded surface. This layer was named by a characteristic black burn-erosion which occurs on the surface due to the burning of the material. Its thickness at die-sinking EDM roughing ranges from 5 to $10 \mu \mathrm{m}$. After die-sinking EDM finishing, BL was not observed to be present. From the metallographic view, BL is created by the metal remnants from the tool SF-Cu electrode, and by the transformed BM.

Another layer of the HAZ of material EN X32CrMoV12-28 after die-sinking EDM with SF-Cu electrode is called the white layer (WL). The name was given by the characteristic white color that results from exposure to high temperature and subsequent rapid cooling of the workpiece surface. This is a highly carburized solidified melt on the surface of a material which is very hard, but brittle. Concerning metallography, WL is formed by nanocrystalline martensite. According to the authors Krastev and Lei $[19,20]$, WL also has good corrosion resistance. WL is formed in die-sinking EDM roughing, as well as in finishing. The difference is in its thickness which ranges from 10 to $40 \mu \mathrm{m}$. The higher values apply to die-sinking EDM roughing, while lower values for the finishing. If the WL thickness exceeds $20 \mu \mathrm{m}$, there is a risk of occurrence of microcracks. These can penetrate up to the $\mathrm{BM}$ and thus reduce the service life of e.g., shearing tools and mold parts produced by this advanced technology. Figure 5 shows metallographic images of HAZ of steel EN X32CrMoV12-28 after die-sinking EDM roughing and finishing. The images were recorded by an electron microscope JEOL 5900 LV (JEOL Ltd., Tokyo, Japan) with magnification 1000×. 


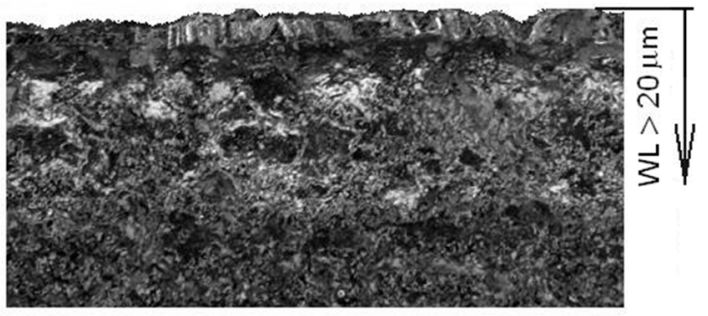

(a) roughing

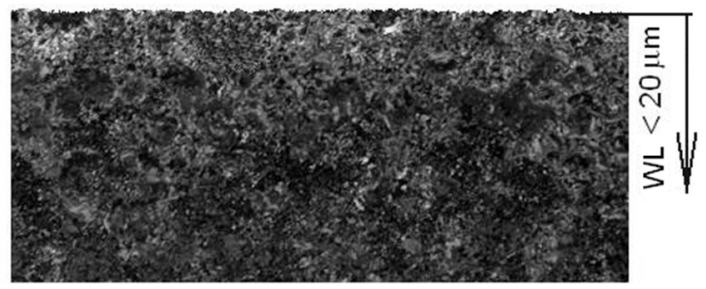

(b) finishing

Figure 5. Total thickness of white layer (WL) in HAZ of steel EN X32CrMoV12-28 after die-sinking EDM roughing and finishing with SF-Cu electrode, recorded by electron microscope with $1000 \times$ magnification.

The third layer in HAZ of material EN X32CrMoV12-28 after die-sinking EDM with SF-Cu electrode is represented by a so-called transition layer (TL). Its name was given due to the gradual change of microstructure and microhardness. Its thickness in the tool steel EN X32CrMoV12-28 ranges from 40 to $250 \mu \mathrm{m}$ (Figure 6). Microstructure and microhardness in TL gradually approaches the parameters of BM. Metallography of TL mostly represents tempered martensite.

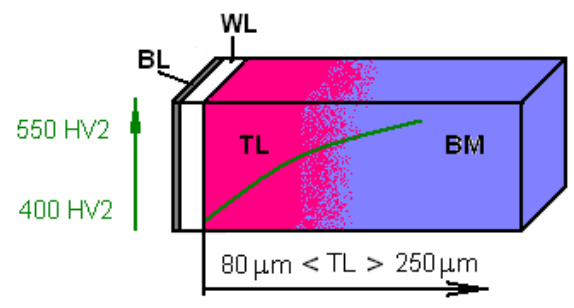

(a) roughing

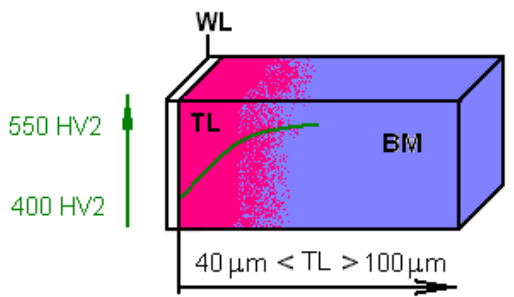

(b) finishing

Figure 6. Total transition layer (TL) depth in HAZ of material EN X32CrMoV12-28 after die-sinking EDM roughing and finishing.

As was already mentioned, crystallographic structure and microhardness of TL and WL differs significantly from the structure and microhardness of BM. In both these layers, predominantly a dendritic structure can be observed, which results from crystallization processes. The extent of the crystallization processes largely depends on the physical properties of the machined material and its chemical composition. The range of the crystallization processes is also dependent on the settings of the main technological and process parameters, as well as on the conditions of dielectric liquid cooling. The presence of two different structures in the HAZ refers to the two-phase solidification process of the molten material during the die-sinking EDM. In the first phase, heat convection occurs with the surface material, due to the impact of thermal energy, which is released by the electrical discharge between the electrode and the machined material. In the second phase, the conductive removal of heat occurs from the material surface by the dielectric fluid and through the subsurface layer to the BM. Even though the structures of TL and WL are not homogeneous, the thickness of WL in the entire cross-section of the eroded surface is approximately constant. On the contrary, the thickness of TL is not constant in the surface cross-section. Its size is largely dependent on the intensity of the discharge energy during die-sinking EDM, and cooling intensity.

In addition to the problem of partial inhomogeneity of the total HAZ depth through the cross-section, there is also the problem of the choice of a suitable measurement methodology. Because the total depth of the HAZ after the die-sinking EDM with SF-Cu electrode is in the order of tens of microns $(\mu \mathrm{m})$ graduation, it presents a certain problem with measurement methodology. Many researchers, from which we can mention Bátora [21], recommend for the detection of 
microhardness and total HAZ depth variation in thin sub-surface layers application of the beveled cross-sections method. However, this method is not suitable in this case, because as the test area is small, it is necessary to use a large angle of the cross-section cut. Such an angle does not guarantee sufficiently relevant results. A more appropriate method therefore seems to be the gradual removal of thin surface layers of material in the thickness range from 5 to $20 \mu \mathrm{m}$. This is a rather difficult and laborious method because it is necessary to make a total of several tens of metallographic sections.

The total numbers of cross-section samples $n_{v c}$ for particular sub-surface layers (BL, WL, and TL), assuming (theoretical) thickness $h_{H A Z}$, were determined by following calculation:

$$
\begin{gathered}
n_{v c}=n_{v B L}+n_{v W L}+n_{v T L} \\
n_{v c}=\frac{h_{H A Z_{t}}-\left(n_{v B L} \cdot h_{v B L}+n_{v W L} \cdot h_{v W L}\right)}{h_{v T L}}+\left(n_{v B L}+n_{v W L}\right)
\end{gathered}
$$

where:

$h_{\text {HAZt }}$-assumed (theoretical) total HAZ thickness,

$h_{v B L}$-facet thickness in BL (for roughing approx. $5 \mu \mathrm{m}$ ),

$h_{v W L}$-facet thickness in WL (for roughing approx. $10 \mu \mathrm{m}$; for finishing approx. $5 \mu \mathrm{m}$ ),

$h_{v T L}$-facet thickness in TL (for roughing approx. $20 \mu \mathrm{m}$; for finishing approx. $10 \mu \mathrm{m}$ ),

$n_{v B L}$-number of facets in BL (for roughing $2 \times$ ),

$n_{v W L}$-number of facets in WL (for roughing and finishing $4 \times$ ),

$n_{v T L}$-number of facets in TL (for roughing and finishing as needed).

In the experimental assessment of changes of microhardness and total HAZ thickness of samples from tool steel EN X32CrMoV12 after die-sinking EDM roughing, with assumed total HAZ depth within the range 105-300 $\mu \mathrm{m}$, it was necessary-according to the formula (2) - to carry out from 10 to 19 metallographic sections on every sample. Concerning samples made by die-sinking EDM finishing with assumed total HAZ depth within the range 50-120 $\mu \mathrm{m}$, it was necessary to carry out from 8 to 14 metallographic sections on every sample. Figure 7 shows the composition of particular metallographic sections of the samples made by die-sinking EDM roughing and finishing.

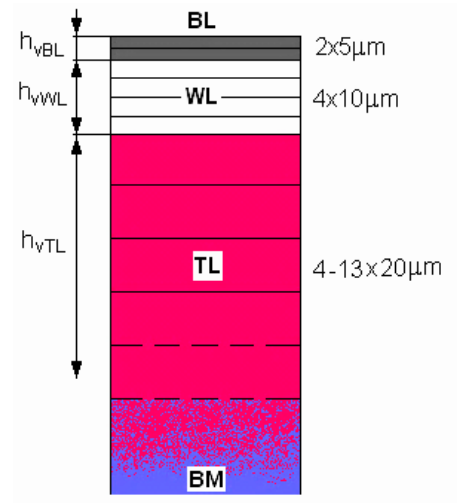

(a) samples after roughing

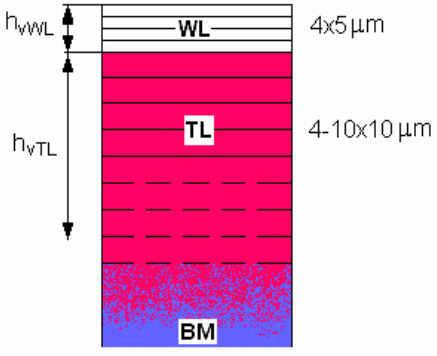

(b) samples after finishing

Figure 7. Composition of experimental metallographic sections for assessment of microhardness change in particular layers, and for assessment of total HAZ thickness of tool steel EN X32CrMoV12-28 after die-sinking EDM roughing and finishing with a SF-Cu electrode.

For an exact assessment of the sub-surface layers microhardness of experimental samples after die-sinking EDM with a SF-Cu electrode, metallographic sections according to Figure 7 were carried out gradually. For samples made by roughing, at first, two metallographic sections with thickness of $5 \mu \mathrm{m}$ were prepared for assessment of BL. Subsequently, another four sections of thickness $10 \mu \mathrm{m}$ were 
carried out for WL assessment. For assessment of WL in samples made by finishing, four sections of thickness $5 \mu \mathrm{m}$ were carried out. For assessment of TL in samples made by roughing, sections of $20 \mu \mathrm{m}$ thickness were carried out, and in samples made by finishing sections of $10 \mu \mathrm{m}$ thickness were carried out. In both methods of machining (roughing and finishing) the metallographic sections were continually prepared for TL assessment until the measured microhardness values HV2 matched the hardness value of BM, i.e., approx. $540 \mathrm{HV} 2$.

In the experimental assessment of total depth and extent of microhardness change in HAZ of tool steel EN X32CrMoV12 after die-sinking EDM with a SF-Cu electrode, it was necessary to take into account the possible dispersion of the recorded values due to the structural composition of the material. This fact is noted by several authors in their research, from which Banker [22] may be mentioned. He states that the course of microhardness and total depth of the HAZ is not constant across all cross-sections of the surface after die-sinking EDM. Because there is a reasonable presumption that the total thickness of the HAZ is not constant across all cross-sections, a pair of indentations was always carried out. The first of the pair of indentations was made on a circle with radius $r_{1}=5 \mathrm{~mm}$, the other on a circle with radius $r_{2}=9 \mathrm{~mm}$. To avoid re-injection of tetrahedral pyramids in the same place at the Vickers microhardness test, each sample was rotated by an angle $\alpha$ of about $20^{\circ}$ after every pair of indentations, according to Figure 8. The experimental microhardness measurements were completed when three successive measured values of the microhardness HV2 of the both indentations stabilized at a constant value, i.e., at the hardness value of approx. $540 \mathrm{HV} 2$ - the value of BM. The total thickness of the HAZ was then determined as the difference between the original height and the height after carrying out of all metallographic sections, values were read on the Digimatic Test Indicator ID-CX Mitutoyo (Mitutoyo, Kawasaki, Japan).

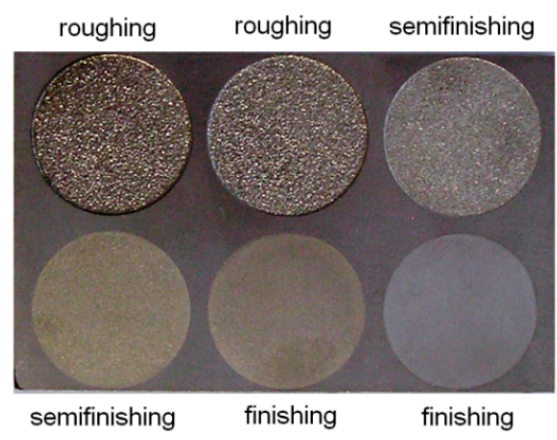

(a) experimental sample

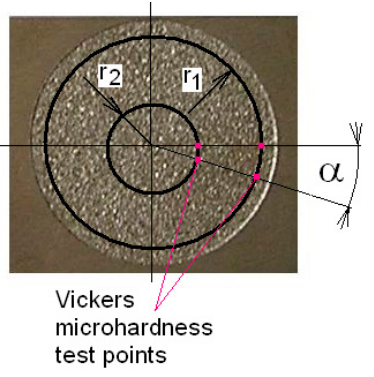

(c) testing of Vickers microhardness

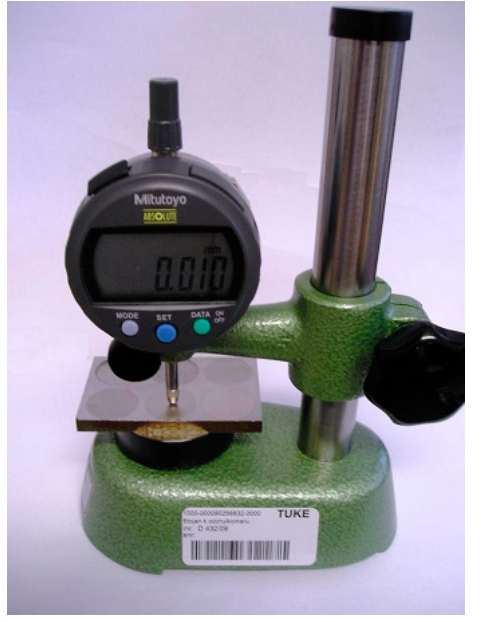

(b) testing of HAZ thickness

Figure 8. Testing of Vickers microhardness and measurement of total HAZ thickness on metallographic section of experimental sample from tool steel EN X32CrMoV12-28 after die-sinking EDM with a SF-Cu electrode.

Measurement of microhardness in HAZ on metallographic sections from experimentally prepared samples made from tool steel EN X32CrMoV12-28 after die-sinking EDM with a SF-Cu electrode was carried out using a device Zwick ZHV30 Vickers Hardness Tester (Zwick GmbH \& Co. KG, Ulm, 
Germany). The measuring range of the given device is HV 0.2 to HV 30. Because the hardness of the BM of tool steel EN X32CrMoV12-28 after heat treatment reaches up to $540 \mathrm{HV}$ (52 HRC), it was not possible to apply Vickers microhardness test according to EN ISO 6507-1 for the measurements [15]. The load in this test is from 0.098 to $1.961 \mathrm{~N}$, which is insufficient for the given BM hardness. With this load, the microhardness can be measured up to the maximum value $464 \mathrm{HV} 0.2$ which corresponds to a Rockwell hardness of approx. 48 HRC. Therefore, the Vickers hardness test at low load HV2 was applied, for which the prescribed load of the tetrahedral pyramid is $19.61 \mathrm{~N}$, according to the standard EN ISO 6507.

\section{Results and Discussions}

The thicknesses of the individual layers of the HAZ (BL, WL, and TL) of tool steel EN X32CrMoV12-28 after die-sinking EDM with a SF-Cu electrode was at first identified on the basis of the microhardness changes. These results were then compared with the results obtained by identification of layer thicknesses based on micro-structural changes. Figure 9 shows the metallographic image of HAZ of tool steel EN X32CrMoV12-28 recorded by the electron microscope JEOL 5900 LV (JEOL Ltd., Tokyo, Japan). Figure 9 shows also the diagram of microhardness HV 2 course after die-sinking EDM roughing at maximum and minimum recorded values of total HAZ depth. The values of microhardness HV 2 in the particular HAZ layers were recorded with a Zwick ZHV30 Vickers Hardness Tester (Zwick GmbH \& Co. KG, Ulm, Germany).

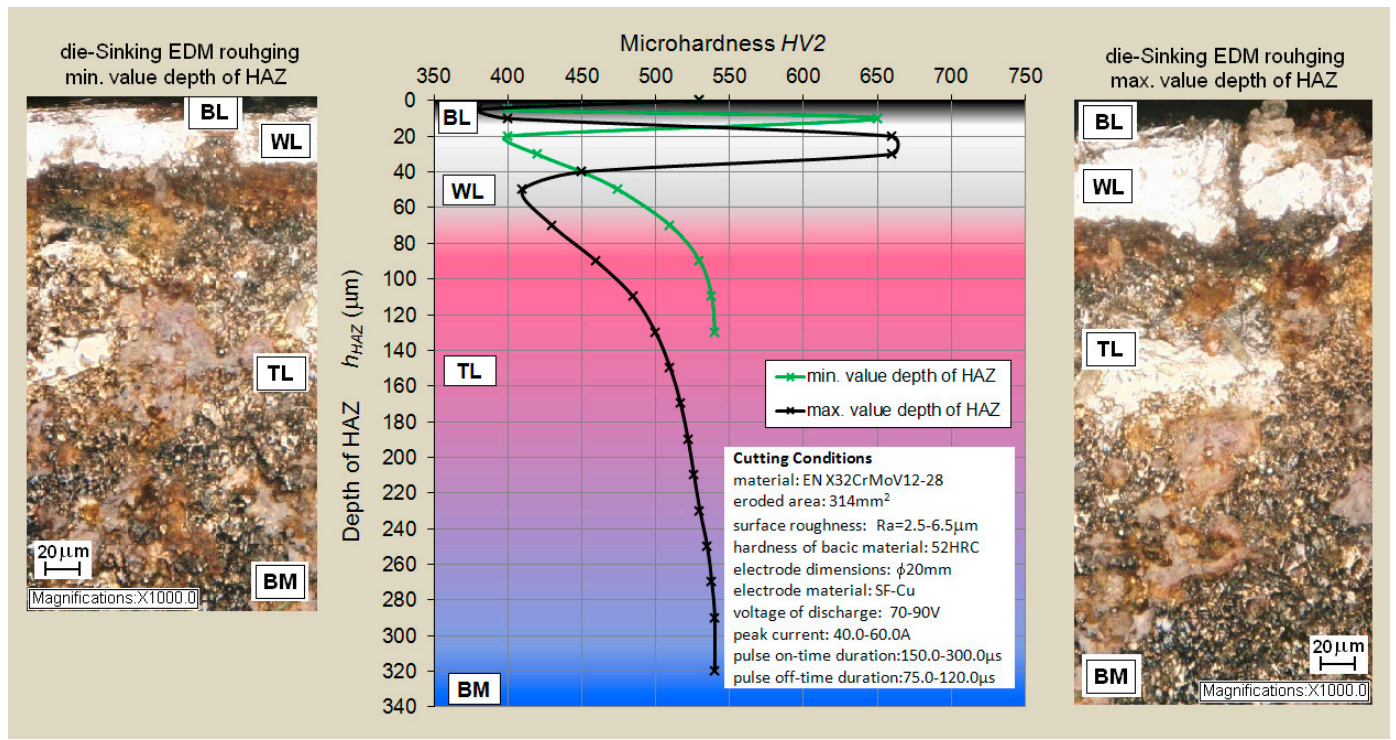

Figure 9. Boundary values of microhardness HV 2 recorded in particular HAZ layers (BL, WL, and TL) of tool steel EN X32CrMoV12-28 after die-sinking EDM roughing with a SF-Cu electrode.

In Figure 9 it can be observed that there are visible microstructural changes in the HAZ of tool steel EN X32CrMoV12-28 after die-sinking EDM roughing with a SF-Cu electrode. The microstructure of these layers differs significantly from that of the BM, as well as from each other. On the image, there are visible small microcracks, i.e., discontinuities which occur predominantly in the WL at the maximum value of the HAZ depth. However, these do not interfere with the TL or BM. The experiment showed the presence of BL directly on the surface of the eroded area. It consisted primarily of transformed BM and metal remnants melted out from the SF-Cu electrode. Visible are also traces left after material burning due to electric discharge, which causes the characteristic black color surface. From the recorded course of microhardness, fluctuations of HV 2 values in particular HAZ layers can be observed, compared to the hardness of BM. Microhardness of BL ranges from 400 to 500 HV 2. Thickness of this layer after roughing operations is between 5 and $10 \mu \mathrm{m}$. Another clearly visible layer 
in HAZ is the so-called white layer (WL). It is located just below BL. In terms of microstructure, WL is formed by nanocrystalline martensite as a result of high discharge energy and subsequent rapid quenching by dielectric fluid $[23,24]$. The resulting martensitic structure is involved in extreme growth of microhardness in WL, up to the level of $600 \mathrm{HV}$ 2. Thickness of this layer at roughing operations ranges from 20 to $40 \mu \mathrm{m}$. Under the well-defined WL which is characterized by its white color, there is a so-called transition layer (TL). This layer is in terms of microstructure mainly composed of tempered martensite, which causes considerable reduction of microhardness [25]. Microhardness of TL stands at about $400 \mathrm{HV} 2$ and with increasing depth progressively approaches the microhardness of BM. The thickness of this layer after roughing operations is between 80 and $250 \mu \mathrm{m}$. Total HAZ thickness at die-sinking EDM roughing with SF-Cu electrode of $20 \mathrm{~mm}$ diameter ranges from about 120 to $280 \mu \mathrm{m}$.

Figure 10 shows the course of microhardness HV 2, and metallographic images of HAZ after die-sinking EDM finishing, at maximum and minimum recorded value of total HAZ depth.

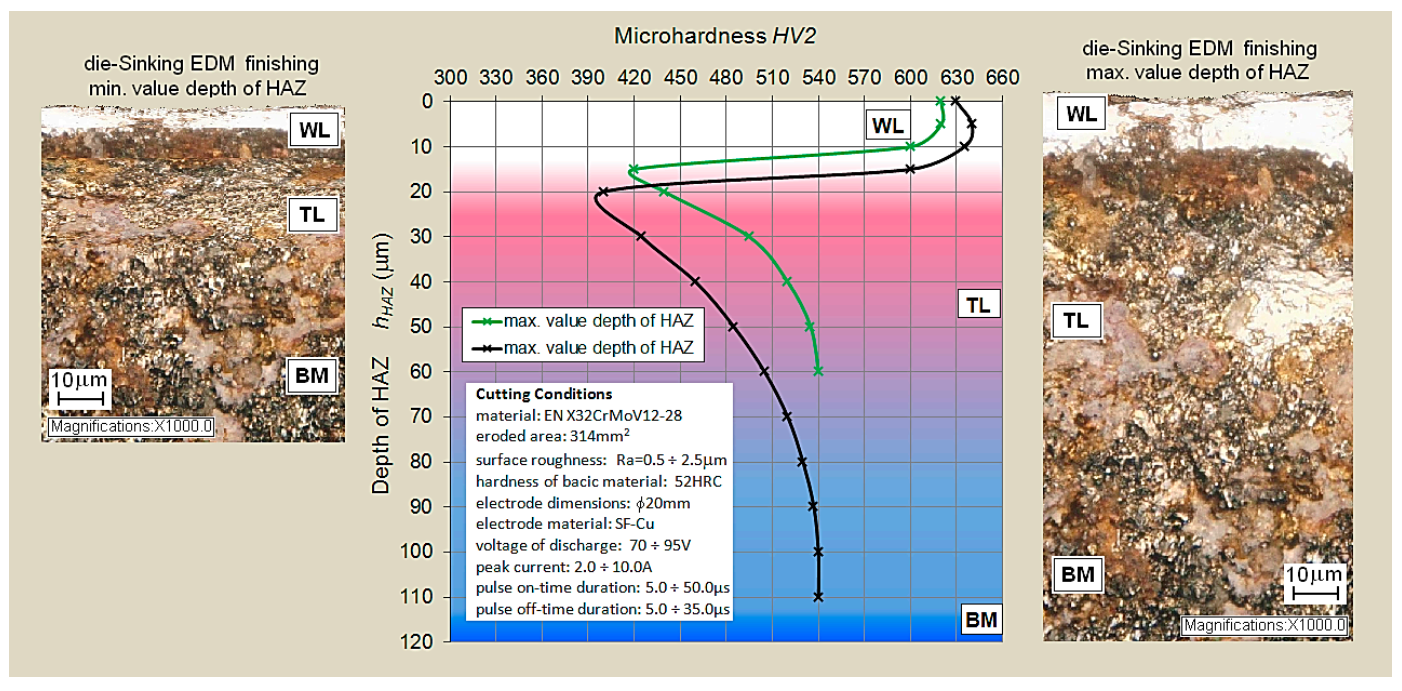

Figure 10. Microhardness HV 2 values recorded in particular HAZ layers (BL, WL, and TL) of tool steel EN X32CrMoV12-28 after die-sinking EDM roughing with SF-Cu electrode.

In Figure 10 it can be seen, as well as in the previous case, that in HAZ of tool steel EN X32CrMoV12-28 after die-sinking EDM finishing with a SF-Cu electrode visible microstructural changes occur. They are, however, to a lesser extent than for roughing operations. There are no visible microcracks or other discontinuities. This is mainly due to a lower discharge energy in combination with the proper heat treatment of BM [26]. The experiment did not show occurrence of BL directly on the eroded surface. Directly on the surface there was the so-called white layer (WL) with its typical character of microhardness increase. The microhardness value of WL ranges from 620 to 640 HV 2 and reaches a depth of about $20 \mu \mathrm{m}$. Below WL there was a so called transition layer (TL) in which microhardness values showed a decrease to levels from 390 to $420 \mathrm{HV}$, and gradually from this value rose until they reached the hardness of the base material (BM) $540 \mathrm{HV} 2$. The thickness of this layer after finishing operations ranges from 40 to $100 \mu \mathrm{m}$. Total HAZ thickness at die-sinking EDM finishing with a SF-Cu electrode of $20 \mathrm{~mm}$ diameter stands in the range from 60 to $100 \mu \mathrm{m}$.

Performed experimental measurements have shown significant effects of the type of die-sinking EDM on the microstructural changes, i.e., whether the roughing or the finishing is observed. Differences were recorded in the BL, WL, and TL. The microstructural changes are of the same nature in roughing, and in finishing $[27,28]$. The essential difference, however, is the extent of the changes. They manifested as microhardness variation, and achieved total HAZ thickness. Significantly lower values of total HAZ thickness were recorded in finishing operations. Differences in achieved microhardness change were recorded also [29]. The extent of the microhardness change was slightly less for finishing operations 
than for roughing operations. In the same time it maintained a steeper characteristic. In particular with HAZ layers, a significant difference between roughing and finishing operations can be observed. It is the absence of BL in finishing operations. In WL after die-sinking EDM roughing, the recorded microhardness values in experimental measurements were on average $40 \mathrm{HV} 2$ higher in comparison with finishing operations. On the contrary, in TL, recorded microhardness values were on average $20 \mathrm{HV} 2$ lower in roughing operations than in finishing operations. The differences were also in total TL thickness. The thickness of TL was significantly less in finishing operations compared with roughing operations.

Based on preliminary studies, relying on the results of other researchers, an assumption arose that there is a difference of total HAZ thickness between intermediate and boundary areas of the eroded surface [30]. In experimental investigations of the eroded surface of tool steel EN X32CrMoV12-28 after die-sinking EDM using a SF-Cu electrode this assumption was confirmed. Figure 11 in graphic form illustrates the differences of total HAZ thickness of a machined surface of $20 \mathrm{~mm}$ diameter from tool steel EN X32CrMoV12-28 after die-sinking EDM roughing and finishing with SF-Cu electrode.

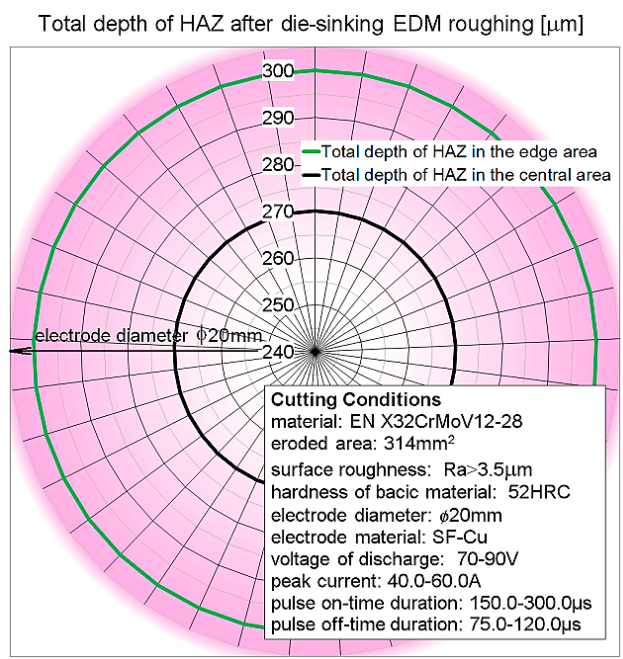

(a) roughing - total depth of HAZ

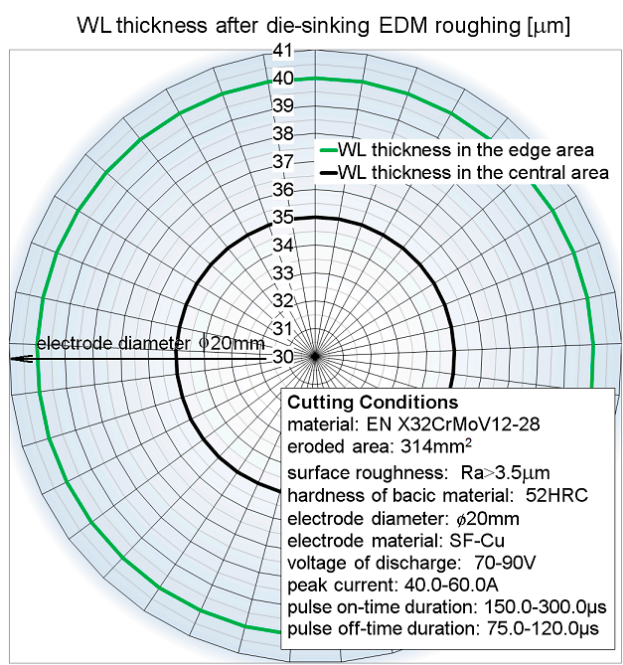

(c) roughing - WL thickness

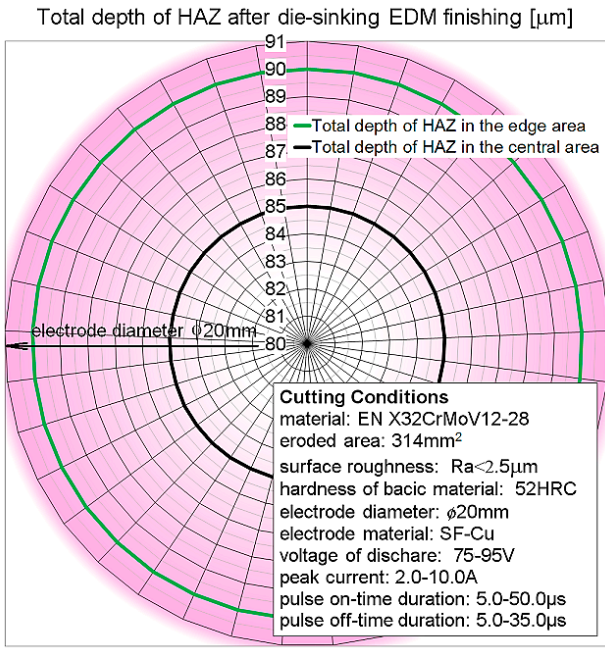

(b) finishing - total depth of HAZ

WL thickness after die-sinking EDM finishing $[\mu \mathrm{m}]$

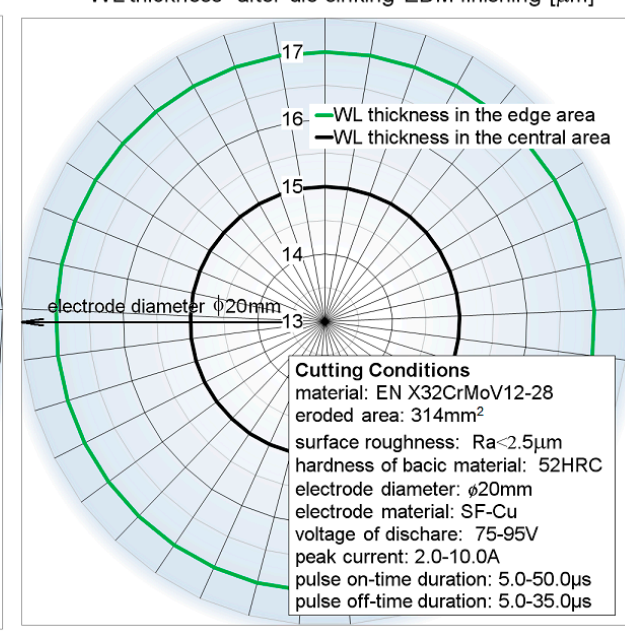

(d) finishing - WL thickness

Figure 11. Recorded differences of total thickness of WL and HAZ of a machined surface of $20 \mathrm{~mm}$ diameter from tool steel EN X32CrMoV12-28 after die-sinking EDM roughing and finishing with a SF-Cu electrode. 
From the plots in Figure 11, small variations of WL thickness and total thickness of the HAZ can be observed between intermediate and boundary areas of the machined surface from tool steel EN X32CrMoV12-28 after die-sinking EDM roughing, and also finishing with a SF-Cu electrode. These variations are obviously caused by excessive overheating of the base material in the middle part, due to the lower cooling intensity of the material by dielectric liquid. This effect is somewhat less pronounced for finishing operations compared to die-sinking EDM roughing because of the lower intensity of electrical discharges. Deviation of the measured values of the WL thickness and the total thickness of the HAZ in the middle and boundary area of the machined surface with $20 \mathrm{~mm}$ diameter was around $10 \%$ for roughing and $5 \%$ finishing operations. Overall lower values were obtained in finishing operations. However, there is a realistic assumption that with increasing eroded surface, such differences will grow even more. This is due to the lower efficiency of the washing out of residues from the point of electro-erosion by dielectric fluid. Therefore, with electrodes of larger dimensions, it is required to set up an additional internal flushing with dielectric fluid.

\subsection{Prediction of HAZ Size of Tool Steel EN X32CrMoV12-28 after Die-Sinking EDM with SF-Cu Electrode}

In practice it is quite an advantage if we can predict the resulting quality of the machined surface of a specific material on the basis of combination of major technological and procedural parameters [31]. Prediction of the quality of the machined surface can be carried out in terms of various indicators [32]. Surface roughness parameters, as well as the total depth of the HAZ or microhardness change can be predicted [33]. However, to ensure that prediction is performed with sufficient accuracy, it is necessary to propose an appropriate mathematical model. For the implementation of the resulting machined surface quality prediction of tool steel EN X32CrMoV12-28 after die-sinking EDM-with a SF Cu electrode in terms of the total HAZ depth, it was necessary to create a mathematical model. Its task is to predict the real relationship between the roughness parameters of the machined surface and the main technology and process parameter settings [34,35]. Since most of the modern CNC electrical discharge machining facilities do not allow selective adjustment of individual technological parameters, so for practical reasons, the roughness parameters relating to the machined surface were included in the model. These parameters reflect the settings of the main technological and process parameters, and at the same time they are coupled to the total HAZ thickness and microhardness change. The mathematical model was constructed using the theory of statistics. The best method for the purpose appeared to be the least squares method (LSM). This method properly approximates the $n$-tuple of the measured parameter values of the total HAZ thickness $\left[h_{H A Z 1}, h_{H A Z 2}, \ldots, h_{H A Z m}, y\right]$ by the function of $m$ variables in the form (3):

$$
y=f\left(h_{H A Z 1}, \ldots . ., h_{H A Z m}\right)
$$

Based on preliminary analysis of the character and distribution of experimentally measured values of total HAZ depth of tool steel EN X32CrMoV12-28 after die-sinking EDM with a SF-Cu electrode, an exponential function with the base of any natural number was chosen for the mathematical model in the formula (4):

$$
y=a_{00} \cdot a_{10}^{h_{H A Z 1}} \cdot a_{01}^{h_{H A Z 2}} \cdot a_{11}^{h_{H A Z 1} h_{H A Z 2}}
$$

while an important condition was that function $S(A)$, which expresses the sum of squares of the differences of calculated and measured values of the total HAZ thickness, in all cases reached its minimum in accordance with formula (5):

$$
S(A)=\sum_{i=1}^{r}\left[y_{i}-f\left(h_{H A Z 1}, \ldots, h_{H A Z m}, A\right)\right]^{2}
$$

Subsequently, the individual values $f\left(h_{H A Z 1}, \ldots, h_{H A Z m}, A\right)$ were replaced by the selected function. Since this is a function of several variables, namely the unknown matrix $A$, taking into account a 
necessary condition of the existence of the extreme of such a function, the first partial derivatives $S(A)$ must equal zero. Then we get the formula (6) for calculating the unknown coefficients:

$$
\frac{\partial S\left(a_{00}, \ldots, a_{r r}\right)}{\partial a_{i j}}=0 \text { for } i, j=0, \ldots, r .
$$

From adjusted partial derivatives, we obtain a set of linear equations, the solution of which are the sought coefficients. The quality of replacement of the experimentally measured values of the particular parameters, provided that its course is described by regression model, expresses the index of correlation, which can be determined by the formula (7):

$$
I K=\sqrt{1-\frac{\sum_{i=1}^{n}\left(y^{\prime}{ }_{i}-y_{i}\right)^{2}}{\sum_{i=1}^{n}\left(\overline{y_{i}}-y_{i}\right)^{2}}}
$$

where $y^{\prime}{ }_{i}$ represents the calculated values according the selected function for $i=1, \ldots, n, \overline{y_{i}}$ is the arithmetic mean of the measured values, and $y_{i}$ are measured values.

In the diagram in Figure 12, the significance of the influence of major technological parameters on the total HAZ thickness in die-sinking EDM can be observed. Assessment of the influence significance was done by factor analysis. The values of the parameters $A, B, C$, and $D$ point to the significance of the effect. The more the values are distant from the mean value of the total HAZ thickness, the higher the significance of the influence of the technological parameter.

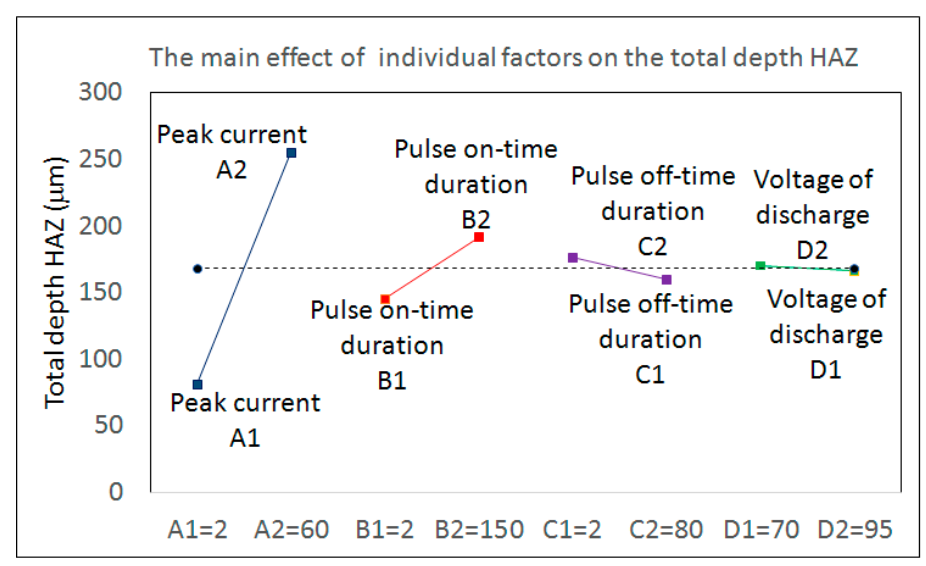

Figure 12. Significance of influence of main technological parameters on the total HAZ thickness at die-sinking EDM.

It can be observed from the diagram on Figure 12, that the greatest influence on the total HAZ thickness at die-sinking EDM is the peak current. On the contrary, the technological parameter, voltage of discharge, proved to have negligible influence and therefore was excluded from further consideration.

Based on factor analysis of the significance of the influence of major technological parameters on the total HAZ thickness at die-sinking EDM of tool steel EN X32CrMoV12-28, for the building of the mathematical model the following was further taken into consideration:

- $\quad$ peak current $I$ ranging from 2-60 A;

- $\quad$ pulse on-time duration $t_{\text {on }}$ ranging from 5-300 $\mu$ s;

- pulse off-time duration $t_{\text {off }}$ ranging from 5-120 $\mu$ s. 
Parameter Voltage of discharge was not recognized in the factor analysis as a parameter that significantly contributes to the nature and size of the total HAZ thickness, therefore, it was not considered for further mathematical modeling.

Prediction of the total HAZ thickness only by mutual combination of the main technological parameters at die-sinking EDM would be very impractical. This is because we need to know the optimal combinations of the main technological parameters to maintain stability and efficiency of the electro-erosion process at die-sinking EDM. As was mentioned above, the machined surface roughness parameters defined in a valid standard EN ISO 4287 after die-sinking EDM are directly related to the main technological parameters. Therefore, the building of the mathematical models proceeded in two steps. First, the mathematical models were established to predict the qualitative parameters of machined surfaces $R a$ and $R z$, based on approximation of the recorded values of technological parameters $I, t_{\mathrm{on}}$, and $t_{\mathrm{off}}$, as sub-models for predicting of the total HAZ thickness. In the second step, a mathematical model was made for predicting the total HAZ thickness on the basis of the qualitative parameters of the machined surfaces $R a$ and $R z$ as a function of seven variables.

I. The mathematical model describing the relationship between main technological parameters and machined surface roughness parameters $R a$ and $R z$, is defined by formula (8):

$$
\text { Ra or } R z=a_{00} \cdot a_{10}{ }^{I} \cdot a_{20}{ }^{I^{2}} \cdot a_{30}{ }^{I^{3}} \cdot a_{01}{ }^{t_{d}} \cdot a_{02}{ }^{t_{d}{ }^{2}} \cdot a_{03}{ }^{t_{d}{ }^{3}}
$$

while parameter $t_{d}$ is defined as a ratio of idling according to the formula (9):

$$
t_{d}=\frac{t_{o n}}{t_{o n}+t_{o f f}}
$$

Subsequently the function of seven variables $a_{i j}$ approximates the set of recorded values $\left[I_{i}, t_{d i}\right.$, Ra resp. $\left.R z\right]$ by the function (10):

$$
\text { Ra resp. } R z=f\left(I, t_{d}, A\right)=f\left(I, t_{d}, a_{00}, \ldots, a_{i j}\right)
$$

where the unknown parameters $a_{i j}, i, j=0, \ldots, r$ are calculated so that the area $S(A)$ best approximates the measured operational values. In this case, we can transform formula (4) into the formula (11):

$$
S(A)=\sum_{i=1}^{n}\left[\text { Raresp. } R z-f\left(I_{i}, t_{d i}, A\right)\right]^{2}
$$

provided that the function reaches its minimum. The unknown in this case, is a matrix of variables $a_{i j}$.

By application of this procedure, there have been proposed mathematical models that describe the array of values of roughness parameters $R a$ and $R z$ of machined surface from tool steel EN X32CrMoV12-28 after die-sinking EDM with a SF-Cu electrode in dependence of significant technological parameters in the formulas (12) and (13):

$$
R a=1.6327 \cdot 1.0984^{I} \cdot 0.9985^{I^{2}} \cdot 1.00001^{I^{3}} \cdot 0.8350^{t_{d}} \cdot 5,6739^{t_{d}{ }^{2}} \cdot 0.0374^{t_{d}{ }^{3}}[\mu m]
$$

correlation index is $I K^{2}=0.9810$

$$
R z=7.4051 \cdot 1.0695^{I} \cdot 0.9991^{I^{2}} \cdot 1.000004^{I^{3}} \cdot 7.5201^{t_{d}} \cdot 0.0029^{t_{d}{ }^{2}} \cdot 16.3326^{t_{d}{ }^{3}}[\mu \mathrm{m}]
$$

correlation index is $I K^{2}=0.9642$

where:

$R a, R z$-are machined surface roughness parameters $[\mu \mathrm{m}]$,

I-peak current [A],

$t_{d}$-ratio of idling, defined by formula (9). 
The accuracy of the proposed mathematical model for prediction of machined surface roughness parameters of tool steel EN X32CrMoV12-28 is represented by the correlation index $I K^{2}$. The index has the value 0.9810 for roughness parameter $\mathrm{Ra}$, and for roughness parameter $\mathrm{Rz}$ it has the value 0.9642 . In both cases, this means a deviation of the predicted values from the actually measured values at the level of about 0.1 to $0.2 \%$.

Based on the implementation of mathematical models (12) and (13) that were prepared in the first step, the 3D diagrams shown in Figure 13a,b were created in simulation program Graphis. These dependencies graphically illustrate the prediction of quality parameters of eroded surface roughness $R a$ (Figure 13a), and $R z$ (Figure 13b) of tool steel EN X32CrMoV12-28 after die-sinking EDM with $\mathrm{SF}-\mathrm{Cu}$ electrode, on the basis of the mutual combination of the significant technological parameters $I$, $t_{\text {on }}$ and $t_{\text {off }}$.

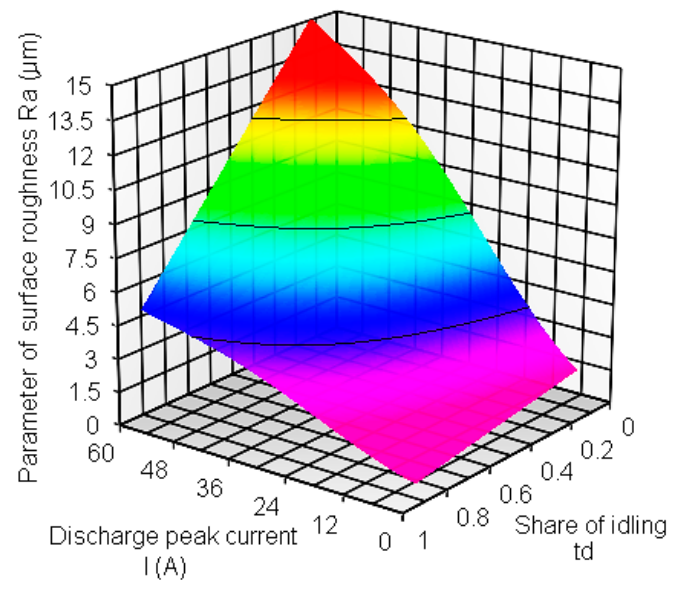

(a) prediction of parameter $R a$

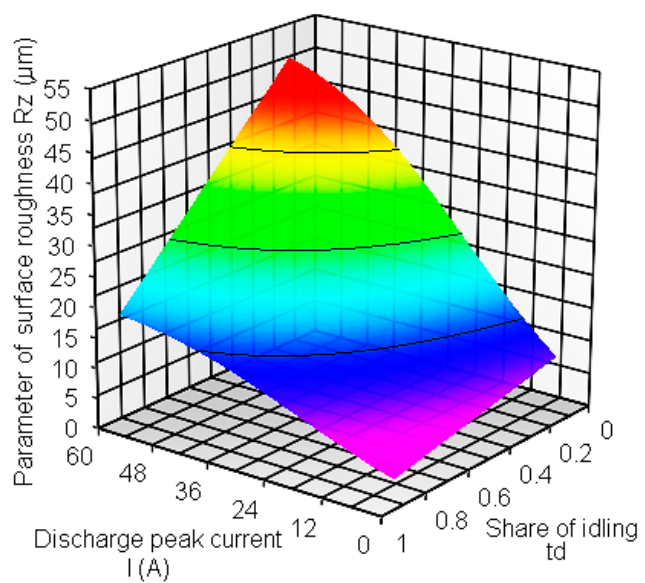

I(A)

(b) prediction of parameter $R z$

Figure 13. Graphical representation of prediction of the surface roughness parameters $R a$ and $R z$ of tool steel EN X32CrMoV12-28 in dependence of significant technological parameters $I, t_{\mathrm{on}}$ and $t_{\mathrm{off}}$ at die-sinking EDM with a SF-Cu electrode.

It can be observed from the graphical dependencies that with an increase of the value of technological parameters $I, t_{\mathrm{on}}$ and $t_{\mathrm{off}}$, there is a substantial growth of the machined surface roughness parameters $R a$ and $R z$ of tool steel EN X32CrMoV12-28 after die-sinking EDM.

II. The mathematical model describing relation between total HAZ thickness and machined surface roughness parameters, is defined by formula (14):

$$
h_{H A Z}=a_{00} \cdot a_{10}{ }^{R a} \cdot a_{20} R a^{2} \cdot a_{30} R a^{3} \cdot a_{01}^{R z} \cdot a_{02}^{R z^{2}} \cdot a_{03}{ }^{R z^{3}}
$$

which approximates the set of experimentally measured values $\left[R a_{i}, R z_{i}, h_{H A Z_{i}}\right]$ by the function according to the formula (15):

$$
h_{H A Z}=f(R a, R z, A)=f\left(I, t, a_{00}, \ldots, a_{i j}\right)
$$

where unknown parameters $a_{i j}, i, j=0, \ldots, r$ are calculated with account of minimization of area $S(A)$. In the given case, we can transform formula (4) into formula (16):

$$
S(A)=\sum_{i=1}^{n}\left[h_{H A Z i}-f\left(R a_{i}, R z_{i}, A\right)\right]^{2}
$$

on the condition that the given function $S(A)$ reaches its minimum. 
Analogously, based on the mentioned procedure, mathematical models were compiled. The models describe an array of parameter values of total thickness $h_{H A Z}$ of eroded surface of tool steel EN X32CrMoV12-28 after die-sinking EDM with a SF-Cu electrode in dependence of surface roughness parameters $R a$ and $R z$ in formula (17):

$$
h_{H A Z}=51.7876 \cdot 1.6772^{R a} \cdot 0.9699^{R a^{2}} \cdot 1.0005^{R a^{3}} \cdot 0.9536^{R z} \cdot 1.00029^{R z^{2}} \cdot 1.0000054^{R z^{3}}[\mu m]
$$

correlation index is $I K^{2}=0.9943$

where:

$h_{H A Z}$-is total thickness $h_{H A Z}[\mu \mathrm{m}]$,

$R a, R z$-are machined surface roughness parameters $[\mu \mathrm{m}]$.

The accuracy of the established mathematical model for prediction of the total thickness of the machined surface $h_{H A Z}$ of tool steel EN X32CrMoV12-28 after die-sinking EDM, is represented by parameter $I K^{2}$ which has value 0.9943 . This presents a deviation of simulated values from actually measured values of total thickness $h_{H A Z}$ on the level up to $0.1 \%$.

Based on the implementation of the mathematical model that was compiled in the second step and is described by formula (17), the 3D graphical dependence (Figure 14) was created in simulation program Graphis. This dependence graphically illustrates the prediction of total thickness $h_{H A Z}$ of tool steel EN X32CrMoV12-28 after die-sinking EDM with a SF-Cu electrode on the basis of the mutual combination of the significant parameters of machined surface roughness $R a$ and $R z$.

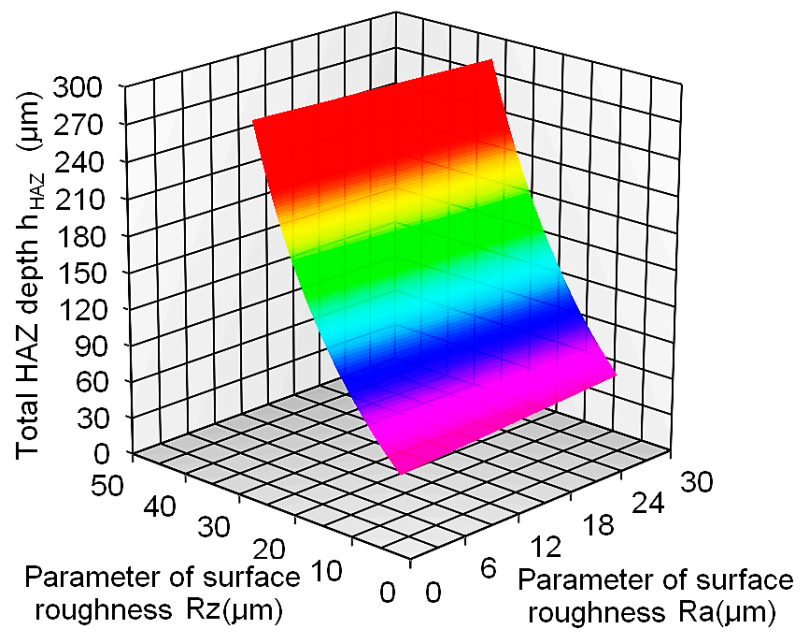

Figure 14. Graphical presentation of prediction of total thickness $h_{H A Z}$ of tool steel EN X32CrMoV12-28 in dependence of mutual combination of significant machined surface roughness parameters $R a$ and $R z$ at die-sinking EDM with a SF-Cu electrode.

From the graphical dependence it can be observed that with increased values of machined surface roughness parameters $R a$ and $R z$ of tool steel EN X32CrMoV12-28 after die-sinking EDM, the total thickness $h_{H A Z}$ grows substantially. At maximum values of roughness parameters $R a(25 \mu \mathrm{m})$, and $R z$ $(50 \mu \mathrm{m})$ it reaches the level of $280 \mu \mathrm{m}$.

Based on preliminary studies, there is a realistic assumption that with an increase of electrode surface, there is also an increase of total thickness $h_{H A Z}$ after die-sinking EDM. Therefore, the last step performed was the prediction of the total thickness $h_{H A Z}$ of tool steel EN X32CrMoV12-28 after die-sinking EDM in dependence on the size of the area of a SF-Cu electrode of a round cross-section of diameter ranging 5 to $60 \mathrm{~mm}$, and roughness parameters $R a$ ranging 0.5 to $2.5 \mu \mathrm{m}$, and $R z$ ranging 2.5 to $50 \mu \mathrm{m}$. The dependence is represented by the 3D diagrams on Figure 15 . 


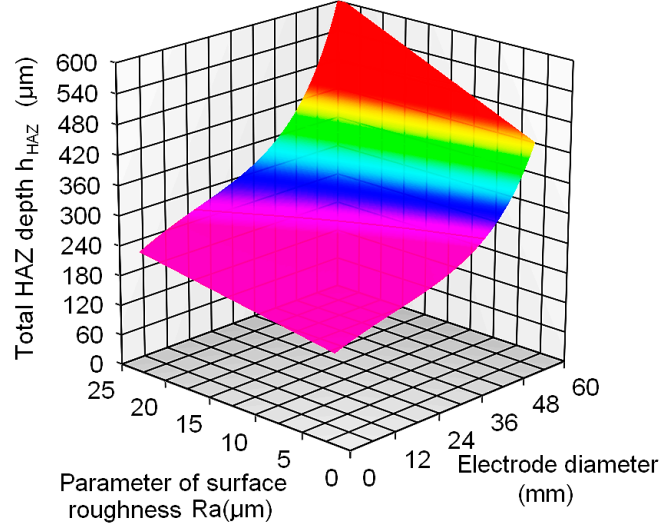

(a) roughing-parameter $R a$

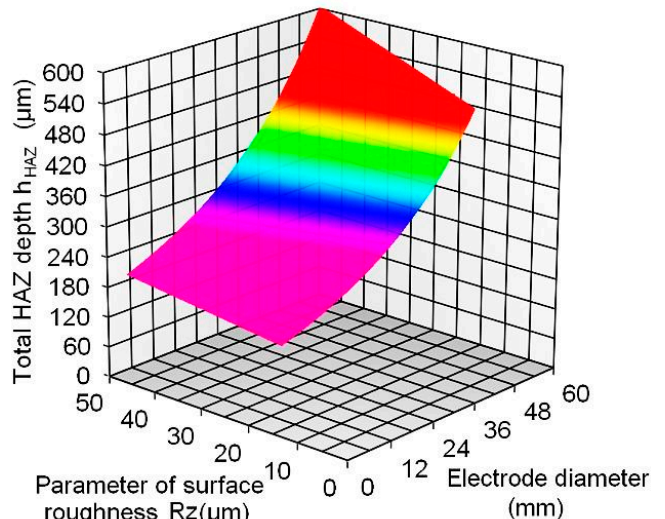

(c) roughing-parameter $R z$

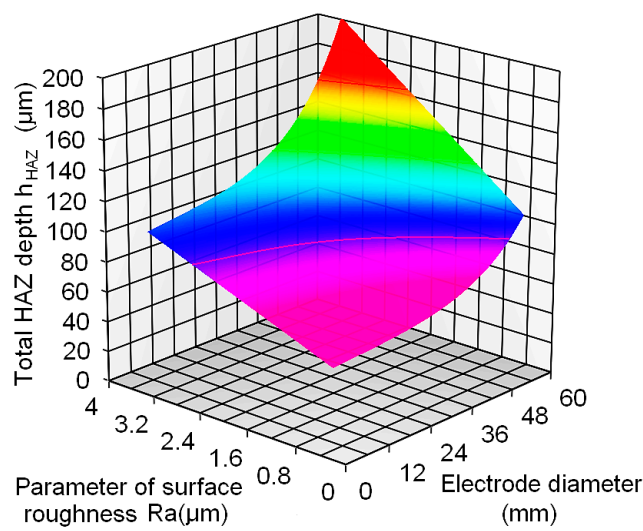

(b) finishing-parameter $R a$

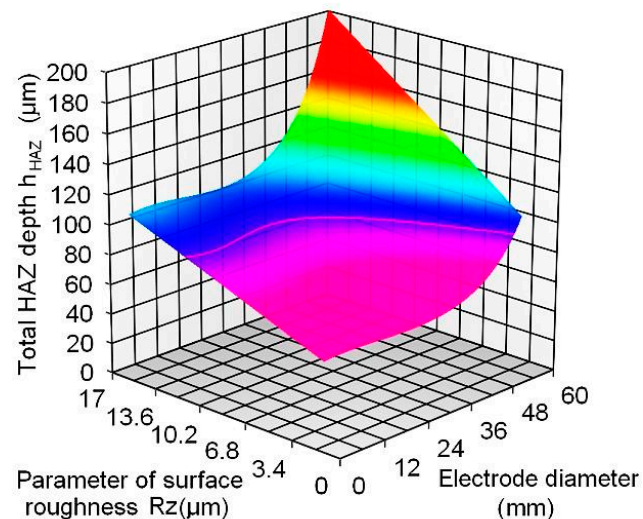

(d) finishing-parameter $R z$

Figure 15. Graphical presentation of prediction of total thickness $h_{H A Z}$ of tool steel EN X32CrMoV12-28 after die-sinking EDM with a SF-Cu electrode in dependence of machined surface roughness parameters $R a$ and $R z$ for an eroded surface of a round cross-section with diameter ranging from 5 to $60 \mathrm{~mm}$.

The prediction of total thickness $h_{H A Z}$ of tool steel EN X32CrMoV12-28 after die-sinking EDM with a SF-Cu electrode was performed for an eroded surface of a round cross-section with diameter ranging 5 to $60 \mathrm{~mm}$. In the eroded surfaces made by a SF-Cu electrode of the given diameter range, the total thickness $h_{H A Z}$ ranges from 50 to $600 \mu \mathrm{m}$ in dependence of significant technological parameters settings that are coupled to the achieved qualitative roughness parameters $R a$ and $R z$ of the machined surfaces. Lower values of total thickness $h_{H A Z}$ are generally achieved with smaller diameters of SF-Cu electrodes and finishing operations. On the contrary, higher values occur in roughing operations, extreme growth of the total thickness $h_{H A Z}$ is present when SF-Cu electrodes with a diameter above $40 \mathrm{~mm}$ are used. Surfaces produced by an electrode with diameter less than $5 \mathrm{~mm}$ are very difficult to verify in terms of total thickness $h_{H A Z}$, so these were excluded from the prediction. Electrodes with diameter larger than $60 \mathrm{~mm}$ are in practice applied mostly with internal flushing, which completely changes the character of the machined surface in terms of variations of microstructure, microhardness, and total thickness $h_{H A Z}$. Surfaces eroded with a SF-Cu electrode with diameter larger than $60 \mathrm{~mm}$ with internal flushing require a specific approach. This approach goes beyond the given experimental research, and therefore was omitted from the prediction.

\subsection{Practical Recommendation for Optimization of Total HAZ Thickness}

Relying on the detailed experimental assessment of changes in microstructure, microhardness, and total HAZ thickness of the tool steel EN X32CrMoV12-28 after die-sinking EDM with a SF-Cu electrode, the significance of the influence of the selected technological parameters [36-40] can be 
confirmed. Technological parameters peak current $I$, pulse on-time duration $t_{\mathrm{on}}$, and pulse off-time duration $t_{\text {off }}$ in factor analysis showed that they have a direct influence on the change of microhardness and also on the overall range of thickness $h_{H A Z}$. The realized prediction of the resulting quality of the eroded surface in terms of total thickness $h_{H A Z}$ using mathematical modeling highlighted the negative impact of the high setting values of the peak current $I$ and the low idling ratio values $t_{d}$ on the essential increase of the total HAZ thickness. At the same time their inappropriate combination has a negative impact on the microhardness change in the sub-surface layers WL, and TL. Suitable combination of settings of the main technological parameters can produce machined surfaces not only with the required surface roughness, but also with the required value of the total depth $h_{H A Z}$. This will improve the quality indicators in all directions. Low total thickness $h_{H A Z}$ has a positive influence on the extent of the structural changes and changes of the microhardness in WL and TL. It is necessary to note, however, that the setting of the main technological parameters must strictly respect the stability of the die-sinking EDM process. In die-sinking EDM, it is also important to take into account its efficiency and productivity [41]. It is therefore convenient to increase the quality of the machined surface with regard to the economic efficiency of the electro-erosion process, while maintaining its stability. One of the solutions of how to minimize the total extent of HAZ in die-sinking EDM of tool steel EN X32CrMoV12-28, is an increase of the setting value of the technological parameter $t_{\text {off }}$. However, to avoid a substantial decrease of the idling ratio $t_{d}$ and the subsequent substantial decrease of cutting performance, it is appropriate to increase the technological parameter $t_{\text {off }}$ by $25 \%$ as a maximum. This results in a slightly longer time to cool the machined surface by dielectric liquid between successive discharges. This leads to a substantially more homogenous microstructure in the HAZ and also to a decrease of the total HAZ thickness. Another problem at die-sinking EDM of tool steel EN X32CrMoV12-28 is an increase of the difference of surface quality with increasing area of the SF-Cu electrode. In the middle of the eroded surfaces the recorded HAZ thickness was approximately $10 \%$ larger compared to the boundaries of the surface. This increase is quite significant for SF-Cu electrodes with diameters larger than $40 \mathrm{~mm}$. Above this threshold, a greater decrease of microhardness in TL occurs. There is a drop of microhardness in comparison with the boundaries of over $20 \mathrm{HV}$ 2. This is mainly related to the lower dielectric liquid cooling effect and therefore the overheating of the material at greater depth [42,43]. A possible solution of how to avoid this undesirable phenomenon in die-sinking EDM with a SF-Cu electrode, is the application of an internal flushing system in the SF-Cu electrodes with diameter larger than $40 \mathrm{~mm}$.

\section{Conclusions}

The research was focused on the experimental assessment of particular sub-surface layers of machined surface of mildly-alloyed chrome-molybdenum-vanadium tool steel EN X32CrMoV12-28 (W.-Nr. 1.2365) after die-sinking EDM with a SF-Cu electrode. The subject of the research was the influence of the main technological parameters on the selected qualitative parameters relating to the individual layers of HAZ. The heat affected zone (HAZ) was investigated in terms of the microstructural changes, changes of microhardness, and thickness of each HAZ layer (BL, WL, and TL). The results of the experiment were oriented on the practical application to achieve a higher quality of machined surface after die-sinking EDM. In practice, great emphasis is often given only on qualitative indicators in terms of machined surface roughness. However, the microstructural changes in the sub-surface layers have a primary effect on the operational functionality, durability, and service life of surfaces machined by the progressive technology of die-sinking EDM. For a more effective applicability of the obtained experimental results in practice, the prediction of the achieved quality was made in terms of the parameters mentioned above. The prediction was made on the basis of mathematical modeling. Implementation of the established mathematical models into the simulation program may serve to predict the total HAZ depth on the basis of the selection of the main technological parameters in die-sinking EDM with different diameters of a SF-Cu electrode. It also 
allows the determination of an appropriate combination of significant technological parameters to achieve the required thickness $h_{H A Z}$.

Summary of experimental research results:

- based on the results of experimental research of sub-surface layers of mildly-alloyed chrome-molybdenum-vanadium tool steel EN X32CrMoV12-28 (W.-Nr. 1.2365) after die-sinking EDM with SF-Cu electrode, the main technological parameters $\left(I, t_{\text {on }}\right.$ and $\left.t_{\text {off }}\right)$ that significantly affect the quality of machined surface in terms of microstructural changes were selected;

- in the heat affected zone (HAZ) three layers (BL, WL and TL) were identified as having a specific microstructure, mechanical, physical, and chemical properties;

- for each layer of HAZ of tool steel EN X32CrMoV12-28 the range of thicknesses, and the microhardness change depending on the setting of important technological parameters in die-sinking EDM with a SF-Cu electrode were determined;

- total thickness $h_{H A Z}$ was determined for the roughing $(120$ to $280 \mu \mathrm{m})$, and finishing operation (60 to $100 \mu \mathrm{m}$ ) with a SF-Cu electrode of $20 \mathrm{~mm}$ diameter;

- based on mathematical modeling the total HAZ thickness was predicted of the tool steel EN X32CrMoV12-28 at die-sinking EDM for SF-Cu electrodes with diameters ranging from 5 to $60 \mathrm{~mm}$;

- there is the possibility of application of established mathematical models for the optimal selection of values of significant technological parameters in die-sinking EDM of tool steel EN X32CrMoV12-28 with SF-Cu electrode of diameter in the range from 5 to $60 \mathrm{~mm}$, based on the required maximum thickness $h_{H A Z}$;

- on the basis of the defined causes, the measures for elimination of the increase of the total thickness $h_{H A Z}$ were proposed;

- on the basis of the defined causes of HAZ inhomogeneity deviations in the middle of the eroded area compared to the area boundaries, reaching a level of $10 \%$, the measures for elimination of the deviations were proposed;

- experimental research of HAZ of the machined surface of tool steel EN X32CrMoV12-28 after die-sinking EDM with a SF-Cu electrode was oriented on the practical application of the results in theory, as well as in technical practice;

- the achieved results of the experimental measurements represent partial results of an extensive set of experimental measurements focused on the creation of a complex database containing data that describe the influence of process parameters on surface roughness and total HAZ depth at die-sinking EDM of tool steels [44];

- the achieved results and proposed solutions concerning prediction make it possible to meet a much closer specification of the requirements, imposed on quality of the machined surface at die-sinking EDM with a SF-Cu electrode.

Acknowledgments: This research work was supported by the Slovak Research and Development Agency under the contract No. APVV-15-0602 and also by the Project of the Structural Funds of the EU, ITMS code 26220220103.

Author Contributions: L'uboslav Straka conceived and designed the experiments; Ivan Čorný and Ján Pitel' performed the experiments; L'uboslav Straka and Slavomíra Hašová analyzed the data; L'uboslav Straka wrote the paper.

Conflicts of Interest: The authors declare no conflicts of interests.

\section{References}

1. Kompella, S.; Moylan, S.; Chandrasekar, S. Mechanical properties of thin surface layers affected by material removal processes. Surf. Coat. Technol. 2001, 146, 384-390. [CrossRef]

2. Ťavodová, M. Research state heat affected zone of the material after wire EDM. Acta Fac. Tech. 2014, 19, 145-152. 
3. Choudhary, R.; Kumar, H.; Gark, R.K. Analysis and evaluation of heat affected zones in electric discharge machining of EN-31 die steel. Indian J. Eng. Mater. Sci. 2010, 2, 91-98.

4. Shrestha, T.; Alsagabi, S.F.; Charit, I.; Potirniche, G.P.; Glazoff, M.V. Effect of heat treatment on microstructure and hardness of grade 91 steel. Metals 2015, 5, 131-149. [CrossRef]

5. Čada, R.; Zlámalík, J. Materials comparison of cutting tools functional parts for cutting of electrical engineering sheets. Trans. VŠB-Ostrava Mech. Ser. 2012, 33-41. Available online: http://transactions. fs.vsb.cz/2012--1/1892.pdf (accessed on 18 April 2016).

6. Švecová, V.; Madaj, M. Surface characteristics evaluation of the VANADIS 23 high speed steel punch after Wire Electrical Discharge Machining. Stroj. Technol. 2012, 40-41. Available online: http://casopis. strojirenskatechnologie.cz/templates/obalky_casopis/XVII_1,2_2012.pdf (accessed on 24 January 2017).

7. Abu Zeid, O.A. On the effect of electro-discharge machining parameters on the fatigue life of AISI D6 tool steel. J. Mater. Process. Technol. 1997, 68, 27-32. [CrossRef]

8. Marafona, J. Black layer characterisation and electrode wear ratio in electrical discharge machining (EDM). J. Mater. Process. Technol. 2007, 184, 27-31. [CrossRef]

9. Ekmekci, B. Residual stresses and white layer in electric discharge machining (EDM). Appl. Surf. Sci. 2007, 253, 9234-9240. [CrossRef]

10. Zang, Y.; Liu, Y.; Ji, R.; Cai, B. Study of the recast layer of a surface machined by sinking electrical discharge machining using water-in-oil emulsion as dielectric. Appl. Surf. Sci. 2011, 257, 5989-5997. [CrossRef]

11. Dewangan, S.; Gangopadhyay, S.; Biswas, C.K. Study of surface integrity and dimensional accuracy in EDM using Fuzzy TOPSIS and sensitivity analysis. Measurement 2015, 63, 364-376. [CrossRef]

12. Sidhom, H. Effect of electro discharge machining (EDM) on the AISI316L SS white layer microstructure and corrosion resistance. Int. J. Adv. Manuf. Technol. 2012, 1-4, 141-153. [CrossRef]

13. Puri, A.B.; Bhattacharyya, B. Modeling and analysis of white layer depth in a wire-cut EDM process through response surface methodology. Int. J. Adv. Manuf. Technol. 2005, 3-4, 301-307. [CrossRef]

14. STN ISO 4287 Surface Roughness Testing. Available online: http://www.gagesite.com/documents/Training/ Mitutoyo\%20Surface\%20Analysis_April\%202\%202014\%20at\%20PQI.pdf (accessed on 17 August 2016).

15. STN ISO 6507 Vickers Hardness Testing. Available online: http:/ /infostore.saiglobal.com/store/PreviewDoc. aspx?saleItemID=40729 (accessed on 17 August 2016).

16. Sodick Technical Specifications. Available online: http://www.sodick.com/products/sinkeredm/ag60l.htm (accessed on 17 August 2016).

17. Material Card of Copper SF-Cu (W.-Nr. 2.0090). Available online: https://www.google.sk/\#q=Material+ Card+of+Copper+SF-Cu+(W.-Nr.2.0090) (accessed on 18 April 2016).

18. Material Card of Steel EN X210Cr12. Available online: http://www.usbcosteels.com/pdffile/OCR12.pdf (accessed on 18 April 2016).

19. Krastev, D. Improvement of Corrosion Resistance of Steels by Surface Modification. Available online: http://cdn.intechopen.com/pdfs/34491/InTech-Improvement_of_corrosion_resistance_of_steels_ by_surface_modification.pdf (accessed on 24 January 2017).

20. Lei, M.K.; Zang, Z.L. Microstructure and Corrosion Resistance of Plasma Source Ion Nitrided Austenitic Stainless Steel. J. Vac. Sci. Technol. 1997, 2, 421-427. [CrossRef]

21. Bátora, B.; Vasilko, K. Obrobené Povrchy (Machined Surfaces); University of Trenčín: Trenčín, Slovakia, 2000; p. 183.

22. Banker, K.S.; Parmar, S.P.; Parekh, B.C. Review to Performance Improvement of Die Sinking EDM Using Powder Mixed Dielectric Fluid. Int. J. Res. Modern Eng. Emerg. Technol. 2013, 1, 57-62.

23. Cusanelli, G.; Hessler-Wyser, A.; Bobard, F.; Demellayer, R.; Perez, R.; Flükiger, R. Microstructure at submicron scale of the white layer produced by EDM technique. J. Mater. Process. Technol. 2004, 1, $289-295$. [CrossRef]

24. Zhang, Y.; Cheng, X.; Zhong, H.; Xu, Z.; Li, L.; Gong, Y.; Miao, X.; Song, C.; Zhai, Q. Comparative Study on the Grain Refinement of Al-Si Alloy Solidified under the Impact of Pulsed Electric Current and Travelling Magnetic Field. Metals 2016, 6. [CrossRef]

25. Ekmekci, B. White layer composition, heat treatment and crack formation in electric discharge machining process. Metall. Mater. Trans. B: Process Metall. Mater. Processing Sci. 2009, 40B, 70-81. [CrossRef]

26. Straka, L'; Čorný, I. Heat treating of chrome tool steel before electroerosion cutting with brass electrode. Acta Metall. Slovaca 2009, 15, 180-186. 
27. Mathew, S.; Varma, P.R.D.; Kurian, P.S. Study on the Influence of process parameters on surface roughness and MRR of AISI 420 stainless steel machined by EDM. Int. J. Eng. Trends Technol. 2014, 2, 54-58. [CrossRef]

28. Straka, L'.; Čorný, I.; Pitel', J. Properties evaluation of thin microhardened surface layer of tool steel after wire EDM. Metals 2016, 6. [CrossRef]

29. Kim, J.M.; Ha, T.H.; Park, J.S.; Kim, H.G. Effect of laser surface treatment on the corrosion behavior of FeCrAl-coated TZM alloy. Metals 2016, 6. [CrossRef]

30. Saha, S.K.; Chaudhary, S.K. Experimental investigation and empirical modeling of the dry electrical discharge machining process. Int. J. Mach. Tool. Manuf. 2009, 49, 297-308. [CrossRef]

31. Das, S.; Klotz, M.; Klocke, F. EDM simulation finite element-based calculation of deformation, microstructure and residual stresses. J. Mater. Process. Technol. 2003, 142, 434-451. [CrossRef]

32. Kiyak, M.; Cakir, O. Examination of machining parameters on surface roughness in EDM of tool steel. J. Mater. Process. Technol. 2007, 1-3, 41-144. [CrossRef]

33. Salonitis, K.; Stournaras, A.; Stavropoulos, P.; Chryssolouris, G. Thermal modeling of the material removal rate and surface roughness for die-sinking EDM. Int. J. Adv. Manuf. Technol. 2009, 40, 316-323. [CrossRef]

34. Ho, K.H.; Newman, S.T. State of the art electrical discharge machining (EDM). Int. J. Mach. Tools Manuf. 2003, 13, 1287-1300. [CrossRef]

35. Mičietová, A.; Neslušan, M.; Čilliková, M. Influence of surface geometry and structure after non-conventional methods of parting on the following milling operations. Manuf. Technol. 2013, 13, 199-204.

36. Amorim, F.L.; Weingaertner, W.L. The behavior of graphite and copper electrodes on the finish die-Sinking electrical discharge machining (EDM) of AISI P20 tool Steel. J. Braz. Soc. Mech. Sci. Eng. 2007, 29, 366-371. [CrossRef]

37. Marafona, J.; Wykes, C. A new method of optimizing material removal rate using EDM with copper-tungsten electrodes. Int. J. Mach. Tools Manuf. 2000, 40, 153-164. [CrossRef]

38. Kopac, J. High precision machining on high speed machines. J. Achiev. Mater. Manuf. Eng. 2007, $24,405-412$.

39. Che Haron, C.H. Investigation on the influence of machining parameters when machining tool steel using EDM. J. Mater. Process. Technol. 2001, 1, 84-87. [CrossRef]

40. Han, X.L.; Wu, D.Y.; Min, X.L.; Wang, X.; Liao, B.; Xiao, F.R. Influence of Post-Weld Heat Treatment on the Microstructure, Microhardness, and Toughness of a Weld Metal for Hot Bend. Metals 2016, 6. [CrossRef]

41. Straka, L'.; Hašová, S. Study of tool electrode wear in EDM process. Key Eng. Mater. 2016, 669, 302-310. [CrossRef]

42. Govindan, P.; Joshi, S.S. Analysis of micro-cracks on machined surfaces in dry electrical discharge Machining. J. Manufacturing Process. 2012, 14, 277-288. [CrossRef]

43. Panda, A.; Duplák, J.; Kormoš, M.; Ružbarský, J. Comprehensive durability identification of ceramic cutting materials in machining process of steel 80MoCrV4016. Key Eng. Mater. 2016, 663, 286-293. [CrossRef]

44. Straka, L'; Hašová, S. Prediction of the heat-affected zone of tool steel EN X37CrMoV5-1 after die-sinking electrical discharge machining. Proc Inst. Mech. B: J. Eng. Manuf. 2016, 9, 1-12. [CrossRef]

(C) 2017 by the authors; licensee MDPI, Basel, Switzerland. This article is an open access article distributed under the terms and conditions of the Creative Commons Attribution (CC BY) license (http:/ / creativecommons.org/licenses/by/4.0/). 